\title{
De la hidrografía imperial a la hidrografía nacional. Reconocimientos del Pacífico sur. Siglos XVIII y XIX ${ }^{1 /}$
}

\author{
From imperial to national hydrography. Expeditions \\ to the south Pacific. Eighteen and nineteenth century
}

Rafael Sagredo Baeza

Pontificia Universidad Católica de Chile

El trabajo identifica las principales etapas del reconocimiento hidrográfico del Pacífico sur y austral frente a las costas de Chile en el lapso de poco más de un siglo a partir de 1786. Ofrece los hitos de este proceso e identifica los objetivos de cada uno de sus protagonistas, los imperios europeos y el Estado chileno. Muestra cómo la necesidad de hacer frente a amenazas, asegurar el comercio y enfrentar querellas de límites están tras la necesidad de levantar el litoral del Pacífico austral.

Palabras Clave: Pacífico sur; Hidrografía; Patagonia; Malaspina; Moraleda; Fitz-Roy; Simpson; Armada de Chile.

This work identifies the main periods of hydrographic expeditions to Chiles' South Pacific coast throughout more than a century starting in 1786. The article highlights the milestones of this process and identifies the objectives of the European empires and the Chilean state. It also shows that the reasons behind the need to gather data about Chiles South Pacific were to confront border conflicts and to secure commerce.

Keywords: South Pacific, Hydrography, Patagonia, Malaspina, Moraleda, Fitz-Roy, Simpson, Chilean Navy.

1 Este trabajo es resultado del proyecto FONDECYT N. ${ }^{\circ} 1130515$, «Los hombres de los límites. La delimitación y demarcación de la frontera chileno-argentina. 1881-1908». 
Hasta 1835 la exploración hidrográfica del Pacífico sur, esto es frente a las costas de Chile, fue una empresa que los españoles en el siglo XVIII y los ingleses en el siglo XIX realizaron de manera sistemática y en función de los intereses de ambos imperios. Más tarde, sería el Estado de Chile, a través de su Armada, el que emprendería el reconocimiento del océano frente a su litoral en general y, en particular, del Pacífico austral, esto es, entre Chiloé y el estrecho de Magallanes, y siempre en el espacio adyacente al continente pues las exploraciones mar adentro fueron escasas. Una empresa poco conocida cuyo objetivo esencial fue estudiar y cartografiar concienzudamente el territorio de la república de Chile.

Los informes, derroteros, planos y cartografía en general de estas comisiones, que constituyen las principales fuentes para su estudio, ofrecen los objetivos esenciales de estos reconocimientos hidrográficos, algunos de sus principales hitos, actores y características; los procesos que se manifiestan a través de ellos; la forma como se relacionan unos con otros; los efectos que tuvieron en la navegación del Pacífico sur; la manera como los aprovecharon científicos, exploradores y navegantes; en definitiva, el papel que cumplió el reconocimiento hidrográfico de España, Gran Bretaña y Chile en la exploración del mayor océano de la tierra.

La evolución entre los reconocimientos imperiales iniciados por España y continuados por la Gran Bretaña, y los nacionales llevados adelante por Chile en la segunda mitad del siglo XIX, muestran que los primeros se contentaron con reconocer y cartografiar el litoral oceánico continental y advertir las principales características de la costa en orden a sus condiciones para fondear naves, hacer aguadas y prever todo lo relacionado con las corrientes, mareas, vientos y fondos, que tan directamente influyen sobre la navegación y sus circunstancias; mientras que la Armada de Chile, además de lo anterior, se ocupó de reconocer cuidadosamente su litoral en general y explorar particularmente la costa austral situada al sur de la isla de Chiloé, así como el interior del continente entre los 44 y 47 grados de latitud sur aproximadamente, teniendo como uno de sus objetivos esenciales la búsqueda de un «paso para la Patagonia». Así, mientras para los imperios la navegación, las rutas y condiciones de la costa resultaron esenciales en función de sus intereses, para el gobierno chileno sería el reconocimiento exhaustivo de territorios y espacios marítimos, para efectos de su aprovechamiento futuro y afianzamiento de su soberanía, la razón última de las comisiones hidrográficas que organizó. 
Preocupación del Estado chileno fue también preparar una geografía náutica de Chile con información de la hidrografía de las costas del país, para lo cual se realizaron exploraciones y organizaron expediciones que, poco a poco, fueron completando el reconocimiento del litoral nacional. En esta tarea se aprovecharon los conocimientos producidos por las comisiones hidrográficas españolas del siglo XVIII e inglesas de las décadas de 1820 y 1830.

En el último tercio del siglo XIX serían la necesidad de obtener antecedentes para enfrentar las querellas limítrofes con Argentina, y la inminencia de un conflicto armado, la guerra desatada contra Perú y Bolivia en 1879, lo que intensificó los afanes chilenos por reconocer las costas del Pacífico sur, preparando de este modo derroteros, informes y otra serie de trabajos que adelantaron en el reconocimiento geográfico e hidrográfico del litoral oceánico.

\section{La hidrografía imperial}

\section{Malaspina en América meridional}

El paso de comisiones científicas por la costa meridional de América del Sur a lo largo del siglo XVIII fue frecuente. Desde Feuillée y Frezier en las décadas de 1700 y 1710 respectivamente, hasta Malaspina y Humboldt, en los últimos decenios de la centuria ilustrada, pasando por Bougainville y La Pérouse, por nombrar sólo algunos, fueron numerosos los navegantes y hombres de ciencia que se aventuraron a reconocer las costas de los virreinatos del Perú y de la Plata y de la gobernación de Chile.

Como testimonio de sus experiencias en esta porción del Imperio español se encuentran sus relatos de viajes, cartas geográficas, informes científicos e iconografía que hoy es posible estudiar para conocer y comprender la realidad americana colonial. Entre todos ellos, sin duda los generados por la Expedición Malaspina, verificada entre 1789 y 1794, son algunos de los más importantes, a la vez que escasamente apreciados hasta hace poco tiempo. ${ }^{2}$

El estudio de la documentación elaborada por la empresa ilustrada encabezada por el comandante de origen italiano permite demostrar que

2 Véase Sagredo Baeza y González Leiva, 2004. 
representa un hito, ya sea que se la considere desde el ángulo del Imperio que la organizó, como del de las colonias y posesiones ultramarinas que recorrió. En primer término, porque en ella se resume un siglo de exploraciones científicas europeas y españolas en América. Ahí están para demostrarlo la magnitud de los recursos reunidos por España en esta comisión ilustrada; la amplitud enciclopédica de los objetivos que se le encomendaron; los vastos espacios marítimos recorridos y los múltiples y heterogéneos territorios visitados; así como por su extraordinaria labor de recopilación de información sobre la realidad natural y social americana y las reflexiones y proyecciones de todo orden que hicieron sus miembros a partir de los conocimientos y experiencias que les brindó América.

Desde el punto de vista de las colonias, la Expedición Malaspina representó un acontecimiento extraordinario, en especial para las sociedades más aisladas y precarias como Chile. Si bien la costa occidental meridional de América había recibido - y continuaría acogiendo - a numerosos y reconocidos viajeros ilustrados como La Condamine, Jorge Juan, Antonio de Ulloa, Vancouver y Heuland, no es menos cierto que a ésta nunca había arribado ni arribaría una empresa de la magnitud de la encabezada por Malaspina y Bustamante, capaz de generar un cúmulo de información como hasta entonces no se había reunido sobre esta sección del continente americano.

La Expedición no tuvo a Chile, Perú o el Río de la Plata como destinos particulares. Malaspina y sus hombres vinieron a las posesiones ultramarinas de España, especialmente a los virreinatos más importantes para la vida económica del Imperio, de tal modo que su paso por la gobernación de Chile, desde antes de su zarpe, representaba una escala más en una derrota cuyo objetivo esencial era conocer América como un todo y en tanto posesión colonial de la metrópoli.

Los científicos ilustrados apreciaron Chile como una frontera política, cultural y económica de vasto alcance, concebida como el espacio geográfico en donde se diluía la influencia de España en América. Los testimonios de los miembros de la Expedición Malaspina sobre Chile aluden a él como a una frontera científica. Un territorio por conocer a través del método propio de la ciencia, por explotar y aprovechar económicamente gracias al conocimiento que se obtuviera de su exploración y estudio. Además, Chile fue apreciado y estudiado en tanto área geográfica que era preciso cautelar militarmente en su condición de primera línea de defensa de las 
posesiones de España en las costas del Pacífico sur, cuando no del océano en su totalidad, en tanto espacio imperial.

La comisión científica de Malaspina debe comprenderse en el contexto de un siglo en el que la ciencia se convierte en un instrumento de expansión imperial, pues la ciencia es poder y éste también se expresa en la capacidad de acceder al conocimiento. Entre ellos, y fundamentales, el progreso en los conocimientos geográficos, náuticos e hidrográficos, con vistas a asegurar la navegación y con ella mejorar la situación económica y comercial del Imperio.

$\mathrm{Al}$ interés por las riquezas de las colonias, las expediciones sumaron el reconocimiento y estudio del litoral americano, especialmente de aquellos sitios que tenían, o podían tener, un valor estratégico desde el punto de vista comercial y militar o que se encontraban amenazados por otras potencias. Este era el caso, por ejemplo, del istmo que media entre el mar Pacífico y el río y golfo de Nicaragua, cuyo «conocimiento cabal debía mirarse como muy importante para la defensa marítima nacional», además de ser «aquel el único desembocadero cómodo para el tránsito a Europa de una porción considerable de frutos preciosos hasta aquí malogrados»; o del extremo meridional de América del Sur, específicamente el cabo de Hornos, que para Malaspina había dejado de ser temible y por lo tanto un fenómeno disuasivo para las naves extranjeras. ${ }^{3}$ Un viaje hecho por navegantes españoles, argumentaron Malaspina y su segundo, Bustamante, antes de zarpar, «debe precisamente implicar la construcción de cartas hidrográficas para las regiones más remotas de la América, y de derroteros que puedan guiar con acierto la poco experta navegación mercantil». ${ }^{4}$ Viajes como el de Malaspina obedecían también a la necesidad de reconocer nuevas rutas para el comercio o localizar bases de apoyo para el mismo. Esto no sólo es válido para las expediciones españolas, sino también para las rusas, francesas e inglesas.

De las organizadas en el siglo XVIII, las expediciones cuya finalidad inmediata se encuentra en el campo de la geografía son las más numerosas. Ello se explica porque durante el siglo XVIII la geografía fue considerada como una de las ciencias que confluía con la náutica. Ambas ciencias se apoyaban para su desarrollo, de ahí que los geógrafos pensaran que los pro-

3 Museo Naval, 1987, II, 1, 135.

4 Véase en Sagredo Baeza y González Leiva, 2004, 161-163, la carta con el llamado «Plan de un viaje científico y político alrededor del mundo» suscrita por Alejandro Malaspina. 
blemas náuticos debían ser estudiados por la geografía. Por su parte, la náutica suponía a su vez la presencia de la geografía, cuyo tratamiento era obligado en los tratados de navegación y pilotaje. La astronomía también formó parte de las expediciones geográficas desde el momento que su propósito fundamental no era estudiar los fenómenos celestes, sino obtener los datos necesarios para conseguir mejores mediciones geográficas y situar exactamente los sitios y puntos de interés.

En su derrota de ida en 1790, Malaspina y sus naves recorrieron el litoral occidental sudamericano desde Chiloé al norte, sin ocuparse de la zona de los archipiélagos y canales australes. Entonces su objetivo esencial fue verificar informaciones de carácter geográfico y económico sobre territorios o rutas, productos o especies que, de confirmarse, representarían grandes beneficios para España. Así, por ejemplo, en su recorrido por las costas chilenas, una vez que había completado sus observaciones astronómicas e hidrográficas en Coquimbo y estando listo para seguir hacia el Perú escribió:

\begin{abstract}
Ya hubiéramos podido emprender de nuevo la continuación del viaje, si la sola hidrografía hubiese sido el objeto de nuestras tareas. Pero el país en el cual nos hallamos, además de contener en sí una cantidad indecible de minas de oro, plata y cobre, había sido también en estos últimos años un objeto de nuevas especulaciones importantes para la Monarquía, con descubrir en las minas no distantes de Punitaqui la esperanza de una nueva suministración abundante de azogue, la cual, o alcanzase a reemplazar los beneficios desmayados de Guancavelica, o tal vez diese en lo venidero las crecidas cantidades que la nación solía recibir de los minerales de Alemania. ${ }^{5}$
\end{abstract}

\title{
Los trabajos geográficos
}

La expedición recorrió las costas de América meridional realizando numerosos levantamientos cartográficos, tanto hidrográficos como terrestres. Entre los hidrográficos están los efectuados en lugares como San Carlos de Chiloé, Talcahuano, islas Juan Fernández, Valparaíso, Coquimbo, islas San Félix y Arica, todos valiosos aportes a la cartografía del territorio de Chile de finales del siglo XVIII, especialmente en lo que dice relación con su precisión en cuanto a la determinación de la latitud y de la longitud. La cartografía preparada, por la naturaleza de la comisión, fue

5 Museo Naval, 1987-1999, II, 1, 90. 
preferentemente hidrográfica o náutica y se materializó en cartas del litoral y puertos, además de perfiles de las costas. La finalidad del trabajo fue llegar a disponer de una cartografía de gran exactitud, que otorgara seguridad en la navegación por los dominios hispanos de ultramar.

Al momento de su llegada a Chile, la cartografía hidrográfica disponible para la jurisdicción correspondiente a la gobernación adolecía de una gran falta de precisión y exactitud. La situación ciertamente no daba confianza a la navegación, especialmente en su parte meridional, la que comprometía el estrecho de Magallanes, el cabo de Hornos y el sector insular inmediato a Chiloé.

En su derrota entre el Atlántico y el Pacífico la expedición bordeó el cabo de Hornos y cruzó el estrecho de Le Maire, estableciendo la situación geográfica de las islas Diego Ramírez y la isla Madre de Dios. Más adelante, hacia el norte, determinó una gran cantidad de puntos con sus respectivas coordenadas geográficas, los cuales se enmarcan en líneas generales entre las islas de Diego Ramírez por el sur y el puerto de Arica por el norte. Hubo puntos relevantes para los científicos cuyas coordenadas se establecieron con gran precisión gracias a la instalación en tierra de una estación con un observatorio portátil. San Carlos de Chiloé, Talcahuano, Valparaíso, Santiago, Coquimbo, La Serena y Arica fueron algunos de ellos. Incluso San Carlos y Coquimbo se consideraron puntos de amarre en la costa occidental de América del Sur, equivalentes a Montevideo en la costa oriental. Ello implicó que las coordenadas geográficas de ciertos lugares estaban referidas, además de al meridiano de Cádiz, al de Montevideo, San Carlos o Coquimbo.

Las coordenadas de los puntos más relevantes levantados por la expedición en Chile, en relación con su situación real respecto del meridiano de Greenwich, ofrecen diferencias en algunos minutos y segundos, resultando que el nivel de precisión de los levantamientos realizados es muy alto. Junto con la triangulación para los levantamientos cartográficos, Malaspina y sus hombres midieron la profundidad y verificaron la calidad del fondo del mar. Con la información obtenida por la expedición fue posible la preparación de una cartografía hidrográfica dentro de la cual se distinguen dos tipos: la que corresponde a planos de puertos, y por lo tanto elaborada a escalas grandes o medianas; y las cartas de un carácter más general, que abarcan grandes extensiones, confeccionadas a escalas pequeñas y denominadas «cartas esféricas». En éstas se utilizó para su construcción la proyección conforme de Mercator. 
El primer plano de un puerto que levanta la Expedición Malaspina en el territorio perteneciente a la gobernación de Chile fue el de San Carlos de Chiloé, considerado lugar principal por los marinos ilustrados. Para su ejecución instalaron un observatorio en tierra y emplearon diferentes instrumentos como el péndulo astronómico, el cronómetro, el cuadrante y el sextante. Aplicaron distintos métodos, como la altura meridiana de las estrellas, para el cálculo de la latitud, y la medición de distancias lunares y el primer satélite de Júpiter, para el cálculo de la longitud, medidas que dieron un valor de $41^{\circ} 51^{\prime} 50^{\prime \prime}$ de latitud sur y $67^{\circ}$ 41' 11" de longitud oeste con respecto al meridiano de Cádiz. Dada la confianza que les merecieron los cálculos efectuados en San Carlos de Chiloé, los científicos adoptaron también el valor del meridiano del lugar como punto de amarre para la continuación de sus tareas hidrográficas. Vale decir, lo tomaron como primer meridiano, al igual que el de Cádiz, para que ante cualquier modificación posterior de las determinaciones astronómicas en la costa occidental de América del Sur, se lo tuviera como referencia.

Al salir de San Carlos para continuar la navegación hacia el norte con destino a Concepción, las corbetas realizaron el trayecto en conjunto y próximas al litoral, utilizando la cartografía levantada por Moraleda. En la ruta se determinaron puntos de interés para la navegación y se delinearon vistas de costas.

Talcahuano, que en un principio no había sido considerado como lugar principal, finalmente fue apreciado como tal. Entonces se hizo el levantamiento del «Plano del Puerto de Concepción», el cual fue publicado el año 1790. Éste muestra la bahía de Concepción y San Vicente en toda su extensión, así como también la isla Quiriquina, registrándose sus profundidades y la toponimia a lo largo de la costa. La escala del plano está dada en millas marítimas, y desde su punto central se indican las direcciones de diferentes puntos con respecto al norte magnético. Desde Concepción la Descubierta se dirigió hacia el archipiélago de Juan Fernández, determinando su posición, y desde ahí a Valparaíso; el curso de la Atrevida hacia Valparaíso se efectuó muy próximo a la costa, circunstancia que hizo posible realizar levantamientos cartográficos y determinar coordenadas geográficas de ciertos puntos, entre ellos Coliumo, un puerto alternativo al de Talcahuano. En virtud que Valparaíso había sido determinado como lugar principal para los efectos de la expedición, se establecieron sus coordenadas geográficas mediante la instalación de un observatorio en tierra. 
Además se levantó el «Plano del Puerto de Valparaíso» por medio de las observaciones hechas con el teodolito.

Coquimbo también fue considerado como lugar principal. Una vez instalados en aquel puerto, los expedicionarios determinaron su posición astronómica en latitud y en longitud mediante la instalación en tierra de un observatorio. La expedición levantó el «Plano del Puerto de Coquimbo» que abarca desde el río Coquimbo por el noreste, donde se localiza la ciudad de La Serena, al puerto de la Herradura por el suroeste, y también ofrece indicaciones de profundidades y alguna toponimia como los islotes Pájaros Niños y Punta de Tortuga, entre otras.

Mientras la corbeta Atrevida salió desde Coquimbo para dirigirse hacia la isla de San Félix, la Descubierta tomó rumbo hacia el puerto de Arica, tocando en lugares como Caldera, la bahía de Mejillones e Iquique.

El puerto de Arica constituía otro de los lugares principales, por lo que se procedió, como en los otros casos a disponer de un observatorio en tierra para determinar las coordenadas geográficas del lugar. Al mismo tiempo se levantó una línea de base para permitir la confección del «Plano del Puerto de Arica» con información acerca del fondo de la rada.

En todos los sitios visitados, especialmente los puertos calificados como lugares principales, se levantaron los planos respectivos y se fijaron, con la mayor exactitud posible la latitud y la longitud, comparándolas con las de otros viajeros como el capitán Cook y La Pérouse. Junto con ese trabajo, se midieron y calcularon las mareas. La preparación de cartas esféricas fue otra de las tareas emprendidas por la comisión de Malaspina. Éstas habían aparecido a mediados del siglo XVI en Europa gracias al cartógrafo holandés Gerhard Kremer, más conocido como Mercator, y en contraposición a las cartas planas en las que la distancia entre paralelos y meridianos es constante, en las cartas esféricas se considera la forma de la tierra como una esfera, por lo que si el distanciamiento entre meridianos es constante, el de los paralelos aumenta del Ecuador hacia los polos. De esta manera se logra representar una parte o la totalidad de la superficie de la tierra, con sus lugares situados de acuerdo a su verdadera latitud, longitud y dirección.

Entre las cartas esféricas de la comisión malaspiniana en que se representa el territorio hoy chileno, destaca la que lleva por título «Carta esférica de las costas de América Meridional desde el paralelo $36^{\circ}$ de latitud sur hasta el cabo de Hornos, levantada por orden del rey, en 1789, 90, 94 y 95 por varios oficiales de su real armada, presentada a su Majestad por mano 
del Excelentísimo Señor Don Juan de Lángara, Secretario de Estado y del Despacho Universal de Marina, Año de 1798». En sus márgenes se indica la graduación de la latitud y la longitud por cada un grado; no obstante, para facilitar la localización de los lugares señalados por la toponimia, preferentemente costera, al estilo de la cartografía portulana, se trazaron las líneas de los paralelos y meridianos cada dos grados. El trabajo realizado representó un gran avance, pues desde entonces se pudo disponer de una carta general de la América austral para fines náuticos, la cual se complementó con el perfil de una serie de vistas, preferentemente de islas a diferentes latitudes, entre las que se encuentran las de Diego Ramírez y Mocha. En la carta también se indican las rutas seguidas por las corbetas Descubierta y Atrevida, tanto en la costa oriental como occidental de la América meridional.

Otra carta de este mismo tipo, es la «Carta esférica de las costas del Reino de Chile comprendidas entre los paralelos de $38^{\circ}$ y $22^{\circ}$ de latitud Sur. Levantada por orden del Rey en el año de 1790 por varios oficiales de la Real Armada, presentada a su Majestad por mano del Excelentísimo Señor Don Juan de Lángara. Secretario de Estado y del Despacho Universal de Marina, Año de 1799». Ella representa una sección de Chile, desde la latitud de Tocopilla por el norte hasta la localidad de Lebu por el sur, registrando graduación en latitud y longitud en sus bordes cada un grado. El meridiano de referencia es el de Cádiz. Tres vistas de costa acompañan la carta: «Vista del Morro de Copiapó dominando al S $43^{\circ} \mathrm{E}$ del mundo, distancia 6 millas»; «Vista del Cerro Purarraque dominando el punto A al S $39^{\circ} \mathrm{E}$ del mundo, distancia 24 millas»; y «Vista de las Tetas de Biobío, dominando la más norte $\mathrm{A}$ al $\mathrm{N} 75^{\circ} 45^{\prime}$ E del mundo, distancia 22 millas». La toponimia es preferentemente costera, indicando puntas, caletas, ríos y puertos. También señala el curso de navegación seguido por las corbetas frente a las costas de Chile.

Ambas cartas esféricas representaron un significativo avance en el conocimiento del diseño de la costa de la América meridional en general, y de Chile en particular. Gracias a ellas se pudo disponer de un mayor número de lugares con determinación de coordenadas geográficas y la cartografía hidrográfica ganó en precisión, confiabilidad y eficacia, haciendo más segura la navegación.

El trabajo astronómico realizado por la Expedición Malaspina en América meridional significó la determinación del posicionamiento de más de treinta puntos a lo largo de la costa de la gobernación de Chile, tanto de 
DE LA HIDROGRAFÍA IMPERIAL A LA HIDROGRAFÍA NACIONAL

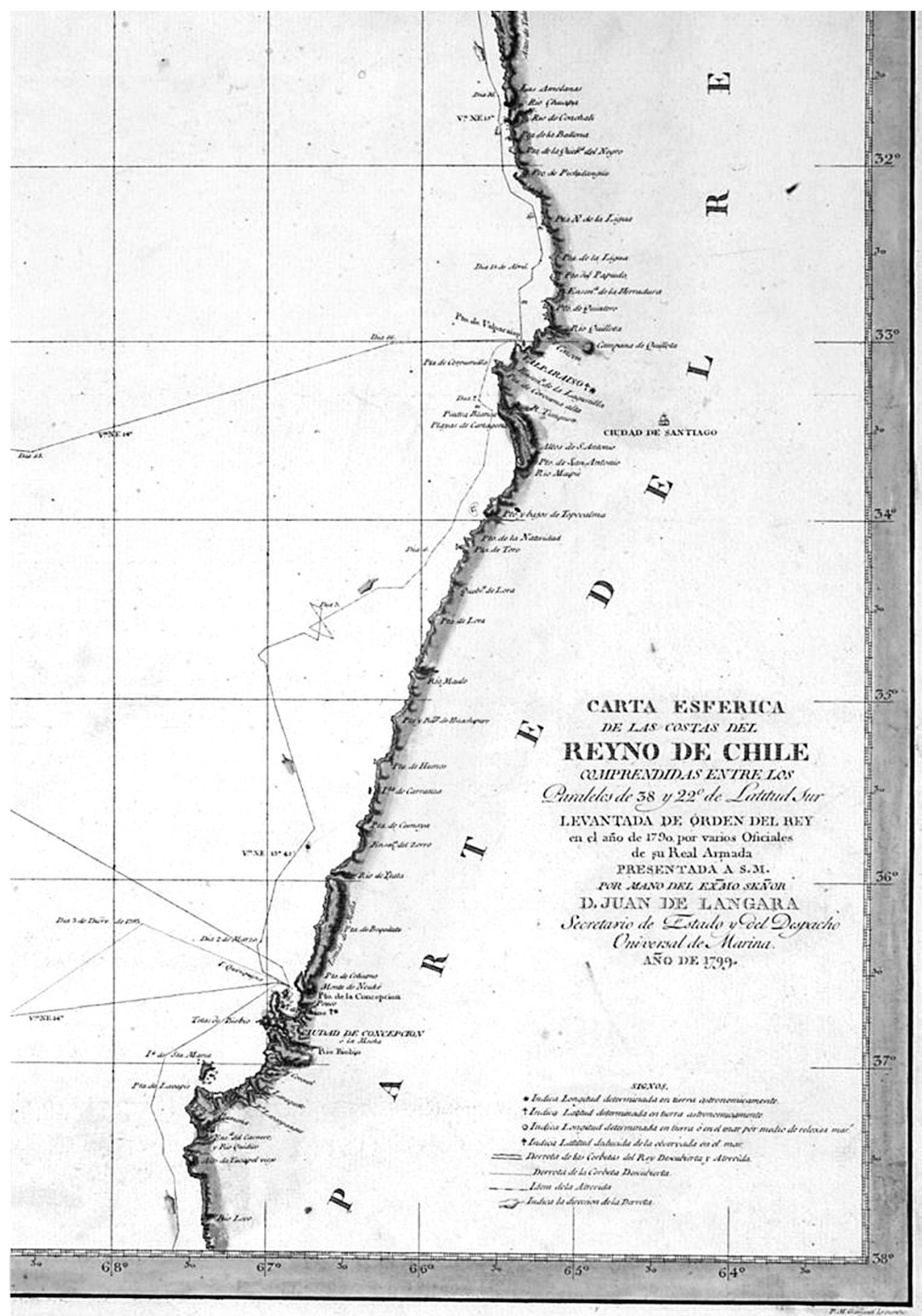

Detalle de la Carta esférica de la costa occidental de América del Sur levantada por los oficiales de la Expedición Malaspina. 
sitios principales como secundarios. Las cartas esféricas a pequeña escala reseñan bastante bien el perfil de la costa y entregan una imagen adecuada de la realidad geográfica del área representada, con las limitaciones propias que la proyección cartográfica del tipo de la Mercator ofrece para latitudes medias y altas. Con todo, la «Carta esférica de las costas del reino de Chile» comprendida entre los $22^{\circ}$ y $38^{\circ}$ de latitud sur, permite localizar con bastante fidelidad los lugares en su correcta posición geográfica y dirección, lo cual representa un notable avance para la cartografía hidrográfica de la época.

\section{El piloto Moraleda en Chiloé y la Patagonia}

En una carta dirigida al ministro de Indias Antonio Valdés, Alejandro Malaspina escribió desde América:

Excelentísimo señor, antes de mi salida de España, los informes de muchos oficiales acreditados de la Armada, y los que había adquirido en Lima al tiempo de venir a las costas del Perú con la fragata Astrea, me habían dado la idea sumamente ventajosa del talento, aplicación y honradez del Primer Piloto graduado Alférez de Fragata, don José de Moraleda. Pero después que he comprobado sus trabajos con los nuestros, he tratado al mismo Moraleda y, últimamente, le he tenido reunido por dos meses para el dibujo de varias cartas y planos, no puedo dejar de hacer presente a V.E. que, realmente, este individuo ha contraído un mérito singular, inclinándose sin objeto alguno de ventajas personales a aumentar sus conocimientos, $y$ a dirigirlos inmediatamente al bien público, en un país en donde, ni debía contar con el auxilio de muchos, ni dejaría de convidarle a la ociosidad los muchos halagos que ésta presenta al recién llegado. La práctica que ha adquirido en esos mares, le debe hacer además muy útil al real servicio y junto a estos objetos justificarán en mí la libertad que ahora me tomo de recomendarlo particularmente a la protección de V.E. ${ }^{6}$

La recomendación de Malaspina contiene todos los elementos que permiten aquilatar la trascendencia de Moraleda y la importancia de sus trabajos. Ahí está su participación en el proceso de exploración y reconocimiento del Pacífico emprendido por España, como reacción a la creciente presencia de ingleses y franceses en un océano que, hasta comienzos del siglo XVIII, prácticamente había sido un lago español; su trayectoria en el Mar del Sur desde que en abril de 1773 arribó al Callao y comenzó sus tra-

6 La nota de Malaspina está fechada en el Callao el 17 de septiembre de 1790 y se encuentra reproducida en Sagredo Baeza y González Leiva, 2004, 301. 
vesías a lo largo de toda la costa sudamericana; también el conocimiento y estudio de las posesiones insulares dispersas entre América y Oceanía; su práctica y experiencia vaciada en la cartografía sobre Chiloé, elaborada en sus campañas por el archipiélago; pero también las cualidades profesionales y humanas que lo habían llevado a servir a la Monarquía sin mayores pretensiones personales y en un medio más favorable a la relajación que al trabajo.

El conjunto de diarios autógrafos de José Moraleda no sólo muestran que el Pacífico sur y el litoral occidental de América meridional fue el espacio en que se desenvolvió durante prácticamente toda su carrera como oficial de la Real Marina Española; también, que las sucesivas comisiones que desempeñaría entre 1772 y 1810 le permitieron realizar estudios muy concienzudos de la costa, rutas y características hidrográficas del Mar del Sur.? Ellos, además, ilustran su papel en el reconocimiento español de las costas del océano Pacífico que, aunque prácticamente olvidado por la historiografía, fue valorado por el más destacado de los marinos al servicio de la Armada Real de la época, Alejandro Malaspina.

Los diarios de Moraleda muestran la aplicación en América de los procedimientos de pilotaje más modernos de su época, fruto de la renovación del conocimiento en Europa. También la recepción y uso de los nuevos métodos para obtener la longitud, como otra serie de saberes que no sólo le permitieron orientar las naves que pilotó, también realizar exploraciones, levantar planos y hacer reconocimientos geográficos que, como los relativos a Chiloé y la Patagonia occidental, tendrían larga vigencia. Sus trabajos ilustran que el piloto realizó a nivel regional lo que España promovió y ejecutó a nivel imperial respecto de sus posesiones americanas. Fue así como exploró, cartografió y delineó islas y archipiélagos, pero también recabó información sobre las características físicas de las zonas exploradas, la población que la habitaba, sus producciones y su situación en el conjunto del Imperio.

7 Los manuscritos del piloto Moraleda son: Viaje al puerto del Callao o de Lima, en la urca afragatada del Rey, del porte de 40 cañones, nombrada Nra. Señora de Monserrate año de 1772, que da cuenta de su paso a América y de sus comisiones por el Mar del Sur entre 1773 y 1779; Viage al reconocimiento de las Yslas de Chiloé. Año de 1786, que relata sus comisiones en el archipiélago entre 1786 y 1790; el Diario de la navegación desde el puerto del Callao de Lima al de San Carlos de Chiloé $y$ de este al reconocimiento del Archipiélago de Chonos y costa occidental Patágonica comprendida entre los 41 y 46 grados de latitud meridional, que cubre sus campañas hidrográficas entre 1792 y 1796; y los Diarios de los viajes desde el puerto del Callao a los de Guayaquil y Panamá, y de estos al reconocimiento y demarcación de las costas de Veragua, Rica, Nicaragua y Guatemala, en los que da cuenta de sus trabajos entre 1803 y 1804 en la costa de América Central. 
La carrera del piloto José Moraleda muestra que desde temprano comenzó a acumular experiencia práctica. Habiendo egresado de la Escuela Náutica de Cádiz en 1764, ese mismo año se embarcó por primera vez en una nave que se dirigió desde Cádiz a Veracruz y La Habana como parte del convoy anual, cumpliendo así con el bautismo práctico que implicaba una travesía transatlántica en su época. Luego de numerosas comisiones, en 1772 fue destinado a la Mar del Sur. ${ }^{8}$ Desde entonces navegó por toda la costa occidental de América del Sur y Central, entre Guatemala y los canales australes, familiarizándose con sitios como Guayaquil, el Callao, Juan Fernández, Valdivia, Concepción, Chiloé, Valparaíso, Arica, Ilo y, en general, toda la costa del virreinato peruano. Entre 1772 y 1786 el piloto español realizó numerosas travesías que sucesivamente lo llevaron desde el Callao a Guayaquil, Juan Fernández, Chiloé, Valdivia y Concepción, además de otros puertos intermedios. Y en 1786 el Virrey de Perú, Teodoro de Croix, lo comisionó a Chiloé para asistir al nuevo gobernador, Francisco Hurtado, en la tarea de levantar un plano grande y general de la isla principal y de las adyacentes, entre otras obligaciones que lo mantendrían en el extremo meridional de América hasta 1795 por lo menos.

La comisión de Moraleda tuvo más de una etapa. La primera, dedicada al reconocimiento de Chiloé, se desenvolvió entre 1787 y 1790 . La segunda, destinada al reconocimiento de la costa occidental patagónica, entre los 41 y 46 grados de latitud sur, se desarrolló entre 1792 y 1795. En el lapso intermedio, Moraleda estuvo encargado en Lima de la instrucción y examen de todos los pilotos mercantes y militares de la Mar del Sur. Un cargo de gran responsabilidad, pues se esperaba que su experiencia permitiera corregir sus diarios y auxiliarles con cartas e informaciones, evitando así «los funestos naufragios habituales». ${ }^{9}$

Entre 1803 y 1804, José Moraleda se desenvolvió en una misión hidrográfica en las costas de Veragua, Nicaragua, Guatemala y los puertos existentes entre Panamá y el de Sonsonate. Durante su trayectoria, y como sus comisiones y cargos lo muestran, Moraleda llegó a forjarse una merecida fama como piloto. Ello explica sus comisiones hidrográficas en Chiloé, la Patagonia occidental y América Central, pero también su dedicación a la enseñanza en Lima. Moraleda murió en 1810 en el Callao, dedicado a la enseñanza de pilotos. Su trayectoria, en el ámbito geográfico en

8 La trayectoria de Moraleda como marino en O'Donnell y Duque de la Estrada, 1990.

9 Según O’Donnell y Duque de la Estrada, 1990, 77, Moraleda llevó a cabo su trabajo «con excelentes resultados». 
que le correspondió actuar, y al igual que la de muchos otros marinos españoles de la segunda mitad del siglo XVIII, forma parte del proceso en virtud de cual España reaccionó para contrarrestar la creciente presencia de otras potencias europeas en sus dominios. Entre las medidas implementadas, el reconocimiento del litoral occidental de América meridional, en particular de Chiloé, la Patagonia y Centroamérica, fueron de las más eficaces.

A lo largo de sus manuscritos es posible apreciar las consideraciones que Moraleda hace sobre su oficio que, reunidas, muestran su concepción del pilotaje, ilustrando de paso sobre esta dimensión del quehacer naval y el alcance de las exploraciones y levantamientos hidrográficos. No sobra mencionar cómo inicia el marino su diario de 1786, en él escribe: «diario de la navegación desde el puerto de Callao de Lima al de San Carlos de la isla de Chiloé, en el que se da noticia de las operaciones practicadas en el reconocimiento de dichas islas y sus inmediatas, con un derrotero a todos los puertos que contienen», haciendo saber así que en él se encontrará, como efectivamente ocurre en todos sus autógrafos con sus travesías, información de todas sus actividades náuticas, hidrográficas y cartográficas, noticias sobre la situación de los lugares recorridos y condiciones de la navegación, características de las mareas, vientos y fondos, y toda otra serie de elementos propios de las singladuras, las derrotas y el medio natural por el que éstas se realizan. Moraleda define claramente su actividad y propósitos cuando en el discurso preliminar del texto con las derrotas a los puertos de la isla de Chiloé asienta:

el modo de dirigirse de uno a otros puertos, a quién el común de los náuticos llama derrota, no es otra cosa que dar noticia de la situación en latitud y longitud de los puertos; de los rumbos a que se ha de llevar el navío, expresando la configuración o señales de las tierras que se deben avistar, con una noticia general de la clase y circunstancias de los vientos que suelen reinar con más frecuencia, y dirección y fuerza de las corrientes o mareas que por lo regular se experimentan, para lograr, cuando no un perfecto conocimiento propio, pues éste se consigue sólo con una dilatada serie de viajes, a lo menos unas nociones o luces que guíen o dirijan a ejecutarlas con el acierto y brevedad que se requiere y de cuya importante ejecución resulte tanto bien al Estado en paz, guerra y comercio.

Una clara noción del significado del oficio de piloto, pues en ella, junto con identificar cada una de sus obligaciones en orden a ofrecer un acabado conocimiento de la realidad geográfica en el que se desenvuelve la navegación, señala claramente cuáles son los propósitos últimos de su acción: proporcionar un saber para el servicio del Estado, tanto en época de 
guerra o paz y, esencial, para el comercio. Todos, objetivos que se prolongarían a lo largo del siglo XIX.

Muestra de su dedicación a las tareas hidrográficas es que el diario que corre entre 1786 y 1790 se inicia con la relación de su paso del Callao a Chiloé, pero su contenido fundamental está dedicado a relatar sus dos campañas desde San Carlos, hoy Ancud, hacia diversos puertos del archipiélago, así como las travesías entre éstos hasta circunnavegar la isla. En la segunda relación está su exploración de los partidos de Calbuco y de Carelmapu y de una sección de la costa continental que circunda el archipiélago. Además de la navegación hacia el Callao, con escala en Valparaíso, una vez concluida su comisión. Esta sección contiene otros dos textos. Se trata de su «Breve descripción de la provincia de Chiloé, su población, carácter de sus habitantes, producciones y comercio», y de los «Acaecimientos de alguna nota ocurridos desde el 17 de julio de 1788 en adelante». Un ejemplo palpable de la capacidad de observación y análisis de un piloto que a través de ellos se muestra como un científico ilustrado, una de cuyas características es la capacidad de describir desde diversas perspectivas una región particular, pero también de proyectarla hacia el futuro a través de la ponderación de sus recursos naturales y humanos, su situación en el conjunto del Imperio y sus oportunidades de desenvolvimiento.

Durante esta primera destinación en el archipiélago de Chiloé Moraleda delineó la configuración de las costas, determinó las condiciones náuticas de los canales, las características de las mareas, las ventajas e inconvenientes de cada puerto y embarcadero y las características de los terrenos adyacentes a ellos, entre otras muchas actividades realizadas. También midió, describió, apreció la realidad geográfica y escribió un minucioso tratado de derrotas para la navegación del archipiélago de Chiloé, diferenciando si la nave entraba por el canal de Chacao o por la boca de Guafo, todo acompañado de reflexiones sobre la situación y ventajas de cada uno de ellos; por último, levantó cartas de las islas, canales y costas que reconoció durante sus exploraciones. Cumplió así con la comisión, tal como él mismo escribió, de «levantar el mapa general del contorno marítimo de esta provincia, las islas contiguas, las costas de tierra firme que le son vecinas, y los planos particulares en escala grande de los puertos que contienen, capaces de guarecer navíos sueltos o escuadras». ${ }^{10} \mathrm{Al}$

10 Las palabras de Moraleda en su manuscrito «Acaecimientos de alguna nota ocurridos...», sección 66, que forma parte de su Viage al reconocimiento de las Yslas de Chiloé. Año de 1786. 
momento de regresar al Callao, Moraleda enumera los mapas que levantó en esta etapa:

[U]n plano o carta hidrográfica reducida que contiene la costa de tierra firme comprendida entre los esteros Maullín y Palena, con inclusión de la isla grande y todas sus inmediatas; otra comprensiva de media isla grande con el camino de Cayucunghen, que conduce desde San Carlos a Castro; otra que contiene la costa intermedia entre este puerto y el río Bueno, donde se incluye el terreno de la antigua ciudad de Osorno y dirección del camino o picado de monte que el año pasado de 1787 hicieron los comisionados a explorar la situación de dicha ciudad arruinada; los planos particulares números uno hasta catorce, que son los puertos de San Carlos, Chacao, Linao, Huiti, Castro, con los canales que conducen a él por las partes del norte y sur de la isla de Lemus, el estero de Ichuac, las bahías de Terao, Queilén, Compu, Huildad, Cailin, Yalad, Calbuco y laguna de Cucao.

La mencionada, sin embargo, no fue la única cartografía que elaboró entonces pues también delineó un plano del puerto de Valdivia y otro de la bahía de Ancud. Además, el propio Moraleda relata que durante el paso de la Expedición Malaspina por Chiloé, ésta recibió «la copia de mi carta general de las costas de esta América», $\mathrm{y}$ «otras dos en punto mayor, comprensiva una de las costas entre este puerto [San Carlos de Chiloé] y el de Valparaíso, y la otra de las inmediaciones de barlovento y sotavento de Lima contenidas entre los 10 y 16 grados de latitud».

La relación de sus exploraciones por la costa de la Patagonia, iniciada con su traslado desde el Callao a Chiloé en septiembre de 1792, incluye las tres salidas que Moraleda hizo desde San Carlos, en enero de 1793 y febrero de 1794 y 1795. En medio ellas se encuentran descripciones de puntos específicos importantes para la navegación como los archipiélagos de las Guaitecas y Chonos, los esteros de Aisén, Palpitad y Comau, el puerto de Santo Domingo, el estero y río Palena, la ensenada de Tictac y el seno de Reloncaví; y derrotas específicas como la que mostraba la forma de llegar al puerto de Santo Domingo por el sur, entrando por Guafo; por último, el apartado «acaecimientos de alguna nota que han ocurrido durante la estancia en el puerto», pone fin a cada una de los diarios de sus campañas.

Gracias a esta comisión Moraleda reconoció sucesivamente la costa de Aysén frente a las Guaitecas, prestando especial atención al río Aysén y a parte del archipiélago de Chonos y de las costas e islas situadas en la costa patagónica occidental hasta los $44^{\circ}$ de latitud sur, en particular, el río Palena. Como en las salidas anteriores, exploró y recogió datos geográficos de una región prácticamente desconocida, todos los cuales expone con claridad 


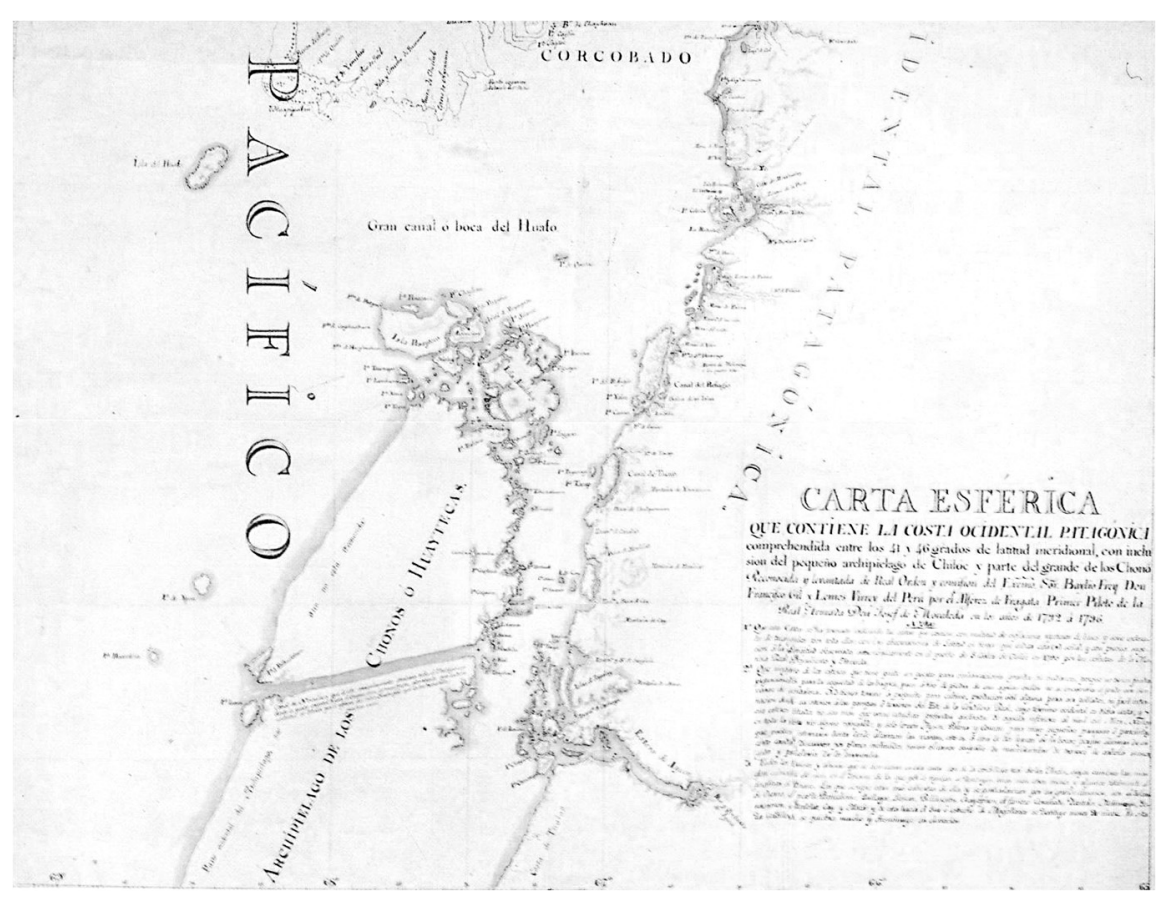

Detalle de la Carta esférica de la costa occidental de la Patagonia levantada por José Moraleda.

y criterio. Sin embargo, en ocasiones, el mismo rigor científico del que Moraleda hizo gala lo llevó a describir y representar la realidad de una manera en que ésta resultaba muy poco atractiva para los intereses imperiales.

De su comisión entre 1793 y 1796 por los canales patagónicos queda el registro en su diario de que a lo menos en la primera parte de ella, no navegó por el mar, como razonablemente se puede creer a partir de las instrucciones recibidas, sino que por canales, esteros y ríos, incluso «ríos de nieve», como el mismo piloto asentó. ${ }^{11}$ En sus resúmenes o breves descripciones de los canales, esteros y ríos reconocidos en la costa patagónica, verdadero informe final de sus exploraciones, José de Moraleda concluyó que el de Aysén no presentaba las condiciones adecuadas para la navegación, siendo ésta «muy molesta, morosa y arriesgada». Del que llamó puerto de Santo

11 Véase en Sagredo Baeza 2010a, la presentación extensa de este problema. 
Domingo, señaló que «respecto de las penurias que hemos advertido en estas agrias costas es abrigado y capaz por su extensión y profundidad de contener a la gira tres de los mayores navíos», pero que siendo casi inaccesibles las entradas sur y norte, «sólo puede ser guarecedero para embarcaciones medianas en un lance extremo». Respecto del estero y río Palena advirtió que en el plano que levantó se «ve lo desapropósito que es para estancia de embarcaciones». Conceptos parecidos expresó respecto de la ensenada de Tictoc, de la que escribió tiene «poca aptitud para la permanencia de embarcaciones de todas clases pues la prolongada constante y grande resaca de sus playas impide aun a las menores atracar». El estero de Palivad también resultaba «muy desapropósito para surgidero de embarcaciones»; y el de Comau o Leteu, «una profunda y estrecha quebrada al interior del mar que hacen a la marina las encumbradas montañas de la famosa cordillera de los Andes, lo mismo que el de Reloncaví y cuantos otros hemos explorado de estas agrias costas en cumplimiento de nuestra comisión».

Con sus palabras José Moraleda canceló, realmente cerró, el espacio y la región que describió a la exploración española, en realidad europea, por un largo tiempo. Sus descripciones de los que llamó «intrincados laberintos» desalentaron el acceso a una zona que se apreció desolada, imposible e inútil para los navegantes; pero que tampoco ofrecía el ansiado acceso al litoral atlántico pues, como concluyó, «no hay en toda la costa río alguno navegable». De este modo, la descripción del piloto, su representación del lugar como canales, esteros y ríos, en vez de promover su apropiación, significó su olvido, una condena a la marginalidad geográfica y política que los marinos chilenos que la exploraron en el siglo XIX no lograron cambiar, y que todavía no concluye.

El piloto Moraleda canceló cualquier viso de interés español por la costa patagónica, «ásperas costas» las llamó, pues, en definitiva, no ofrecían «puerto a propósito para guarecerse embarcaciones grandes o medianas», que era precisamente lo que él había estado buscando. Un litoral que además describió como «un terreno compuesto por altas montañas escarpadas, organizadas hasta su superficie de rocas horribles y nevadas», caracterización que tampoco alentó nuevos reconocimientos de la zona. Así quedó desacreditada por la ciencia ilustrada la dimensión político estratégica de la Patagonia occidental, entre otras razones, por ser más semejantes sus condiciones naturales a las de un río de bordes escarpados y curso cerrado, que a las de un mar abierto, como los trabajos hidrográficos del piloto Moraleda demostraban. 


\section{Fitz-Roy y el Beagle en América meridional}

Salvo por las regiones polares, a comienzos del siglo XIX la forma general del globo terrestre era conocida en sus rasgos generales, pero quedaban por determinar numerosos detalles. Respecto de las costas, muchos de sus contornos estaban dibujados a grandes trazos y se requerían observaciones minuciosas y precisas para delinearlas con precisión y por lo tanto dar seguridad a la navegación.

Habiéndose resuelto a lo largo del siglo XVIII el problema de la longitud gracias a los cronómetros, capaces de conservar con precisión en las naves la hora del primer meridiano que comparada con la del lugar daba la longitud exacta, y perfeccionado la forma de calcular la latitud, se inició la tarea de completar los resultados de las grandes travesías de descubrimiento y de, además, situar exactamente la situación de los lugares conocidos. Las nuevas comisiones no tuvieron como fin descubrir tierras nuevas, sino atender a los detalles y rectificar, con el propósito de esclarecer la ciencia geográfica. También completar el reconocimiento de regiones poco conocidas todavía, en particular, en el Pacífico. En esta empresa del siglo sobresalieron ingleses, franceses y rusos, en los que serían los últimos años de la navegación a vela y de los viajes de circunnavegación. Entre ellos, el protagonizado por Robert Fitz-Roy a bordo del Beagle y con Charles Darwin como naturalista.

En la dedicatoria de 1839 al Primer Lord del Almirantazgo con que Robert Fitz-Roy encabeza la publicación de las exploraciones emprendidas por el Adventure y el Beagle entre 1826 y 1836, escribe que ella contiene «la narración de los viajes de levantamiento» que ambas naves realizaron por orden del Consejo del Almirantazgo, señalando así en la primera página de su relación la naturaleza de la empresa en que había participado. El texto era el resultado de nueve años de viajes por «costas mal conocidas», en los que se realizaron dos campañas hidrográficas: una entre 1826 y 1830, y otra entre 1831 y 1836. La primera encabezada por el capitán Phillip Parker King, la segunda al mando de Fitz-Roy, y en la cual participaría Charles Darwin como naturalista. Ambas destinadas a cartografiar las costas meridionales de América del Sur.

En las instrucciones originales, que datan de mayo de 1826, al comandante hidrógrafo jefe de la expedición, Phillip Parker King, se le comisionó para un «levantamiento exacto de las costas meridionales de la península de Sud América, desde la entrada sud del Río de la Plata hasta Chiloé, y 
Tierra del Fuego». En particular se le ordenó «levantar las costas, islas y estrechos hasta Chiloé». ${ }^{12}$ También se le encargó aprovechar «toda oportunidad para coleccionar y conservar muestras de ejemplares de historia natural que sean nuevos, raros o interesantes».

La necesidad de abrir rutas comerciales, asegurar el tráfico y conocer la posición exacta de los principales accidentes geográficos del litoral meridional sudamericano, explican los afanes ingleses; los que también se justifican en la necesidad de modernizar una Armada hasta hacía pocos años más concentrada en la guerra que en la exploración y el levantamiento de las costas. El objetivo esencial del Almirantazgo fue, en la comisión de 1826 a 1830, obtener un reconocimiento geográfico e hidrográfico lo más acabado posible de la costa meridional de América, al que posteriormente se agregó, en la de 1831-1836, completar una circunnavegación que permitiera aprovechar los cronómetros marinos que Fitz-Roy llevó a bordo de sus naves. Y, junto ello, tratar de descubrir un «puerto que permita fondeadero seguro y saludables aprovisionamientos en la costa patagónica atlántica», así como la «investigación particular del estrecho de Magallanes y del intrincado grupo de islas que forman la Tierra del Fuego», en especial en lo relativo a identificar y situar exactamente los obstáculos para la navegación existentes a la entrada del estrecho, determinar sus detalles interiores, medir las profundidades, dilucidar dudas sobre la disposición y características de algunos canales, islas, senos, rompientes, entradas y, sobre todo, la identificación de algún buen puerto pues, como se advirtió a Fitz-Roy, «No puede dejarse de repetir a menudo que en la región más inhóspita, lo más valioso es un puerto de refugio conocido». ${ }^{13}$

Fuera del estrecho, en el Pacífico, Fitz-Roy debía explorar el litoral oceánico de las islas que se extendían hacia el norte, hasta el Golfo de Penas, eliminando así el que se consideraba un «vacío» cartográfico. Como desde Chiloé al norte la costa es recta y casi en la dirección del meridiano, las instrucciones fueron corregir el contorno y fijar la posición de todos los puntos salientes.

Los objetivos políticos de la expedición se relacionan con la necesidad de satisfacer propósitos nacionales, como por ejemplo el desarrollo del Imperio a través del establecimiento de apoyos, bases firmes, en el área, y la protección de los ciudadanos e intereses británicos, fomentando de este

12 Fitz-Roy, 2009, 31-33.

13 Fitz-Roy, 2013, 43-53. 
modo la red colonial o imperial. Cartografiar América permitiría a su vez tomar decisiones bien informadas sobre operaciones navales, militares y comerciales, todas esenciales para la expansión económica británica, pues, como se afirmaba entonces: «el comercio es el dictador oculto del levantamiento hidrográfico». ${ }^{14}$

Las consideradas limitaciones y falencias de la cartografía española también alentaron a los ingleses a emprender sus exploraciones por las costas de América del Sur. En esta tarea no sólo cartografiaron la costa, también midieron la profundidad del agua en múltiples puntos, instalaron instrumentos para determinar la posición relativa de los principales accidentes geográficos y recolectaron todo tipo de especies naturales, advirtiendo de las principales características de los territorios y poblaciones que encontraron a su paso, continuando de este modo con la tradición ilustrada que los españoles habían iniciado en el siglo XVIII.

En los mares australes los británicos estudiaron el estrecho de Magallanes y el archipiélago costero occidental, en especial las Guaitecas y Chonos, la península de Taitao y Guayaneco. ${ }^{15}$ En la primera campaña se concentraron en la sección septentrional de la región de Magallanes, en particular las islas Campanas y Guayaneco y sus alrededores, extendiéndose hacia el golfo de Penas, Tres Montes y la costa meridional de la península de Taitao. En la comisión encabezada por Fitz-Roy a partir de 1831, el archipiélago de los Chonos concentró la atención de los ingleses entre junio de 1834 y febrero de 1835, que recorrieron la costa exterior de los Chonos, desde Guafo a Tres Montes, levantando de este modo el litoral oceánico de la región. Siempre contrastando sus observaciones con las de Moraleda, los británicos reconocieron canales e islas buscando siempre caletas apropiadas y estableciendo o rectificando coordenadas geográficas.

El principal legado cartográfico de los ingleses se presenta respecto del litoral occidental entre puerto Low y el archipiélago Guayaneco, siendo una muestra la toponimia que heredaron como los canales Darwin, King y Chaffers, las islas Level, Broken, Johnson, Forsyth, Midhurs, Mellersh y Arthur, y la bahía Adventure, entre otras. Junto a las exploraciones, el resultado más notable de las campañas inglesas en los mares australes fue el descubrimiento del canal Beagle, uno de los tres pasos naturales entre el Atlántico y el Pacífico, y situado al sur de Tierra del Fuego en sentido este a oeste.

14 Citado por Gribbin 2006, 40.

15 Véase Hidalgo Canales, 2013, 36-46. 


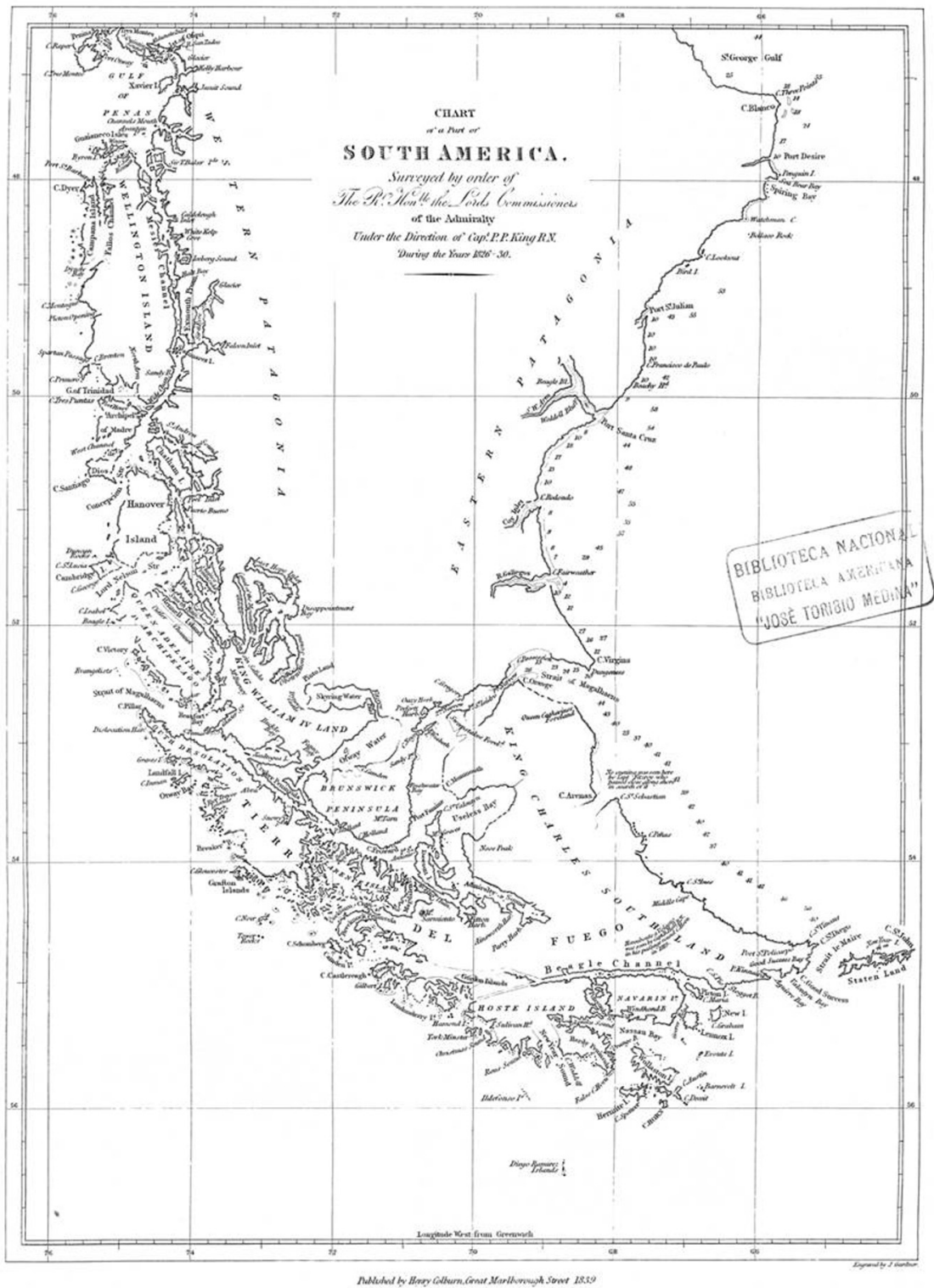

Parte de la costa de Sudamérica levantada por las comisiones hidrográficas inglesas en las que participó Robert Fitz-Roy. 
El producto de las comisiones hidrográficas en que participó el capitán Fitz-Roy fue un conjunto de cartas, ochenta y dos del litoral y ochenta planos de puertos, que se emplearon durante más de un siglo como fuente de información fidedigna sobre las aguas de Tierra del Fuego y sus inmediaciones. ${ }^{16}$ Sería el propio Robert Fitz-Roy quien, en una conferencia en la Royal Geographical Society resumió su comisión. «Empezando en la orilla derecha o meridional del ancho Río de la Plata, exploramos minuciosamente cada milla de la costa desde allí hasta el cabo de Hornos, junto con las islas Malvinas. Y aunque al oeste del cabo de Hornos no hubo necesidad de completar mucho el levantamiento hidrográfico realizado durante el viaje anterior del Beagle hasta los 47 grados sur, desde esa latitud hasta el río Guayas, se ha explorado todo el litoral de Chile y de Perú; no se ha omitido ningún puerto o fondeadero». ${ }^{17}$

De regreso en Inglaterra, y junto a la cartografía, instrucciones de navegación y material relativo a su viaje, Robert Fitz-Roy trabajo en la preparación de un libro en el que dio cuenta de las comisiones en que participó entre 1826 y 1836 , presentando un recuento completo del primer viaje y la narrativa del segundo que él comandó a bordo del Beagle. La edición en tres tomos y un apéndice se tituló Narrative of the Surveying Voyages of His Magesty's Ships Adventure and Beagle, apareció en 1839 y constituye una fuente esencial para el conocimiento de la empresa hidrográfica llevada adelante por los ingleses en América del Sur. ${ }^{18}$ En ellos, además de las alternativas de la expedición, se encontrarán reflexiones generales de Fitz-Roy sobre diferentes fenómenos, como por ejemplo, la corriente de Humboldt que el sabio prusiano había identificado a comienzos del siglo XIX.

Aludiendo a las corrientes alrededor de las islas Galápagos, y sobre todo a las notables diferencias de temperatura de las masas de agua que se movían a pocas millas unas de otras, escribe que era una cuestión que debía «reservarse para mayor examen», aunque agregaba que tal vez «estas asombrosas diferencias pueden deberse a la corriente fría que viene desde

16 Incluso entre quienes deben ser considerados sus competidores, la tarea hidrográfica de los ingleses fue apreciada. Así lo dejan ver los juicios de J.C. Dumont D'Urville quién, en el relato de su viaje al Polo Sur y Oceanía, escribió a proposito de los trabajos de King y Fitz-Roy: «Las operaciones de ambos capitanes produjeron una serie de mapas que dibujaron de la manera más detallada y más satifactoria posible la configuración de esta multitud de islas, islotes y canales que cortan la punta meridonal de América». Véase Urville, 2011, 52. 311-343.

17 La conferencia se publicó en el Journal of the Royal Geographical Society, vol. 6, 1836,

18 El tomo tercero de la obra es el relato de Charles Darwin conocido como Viaje de un naturalista alrededor del mundo, objeto de múltiples ediciones y traducciones. 
el sur a lo largo de las costas de Perú y Chile, y encuentra en las Galápagos una gran masa de agua mucho más cálida, que se mueve desde la bahía de Panamá, una clase de "corriente del golfo"». Apuntando todavía que, «se ha observado con frecuencia la manera retentiva en que esos ríos oceánicos preservan su temperatura; y debe tener gran efecto sobre los climas de los países cerca de cuyas costas fluyen». ${ }^{19}$ Las palabras del marino inglés demuestran que habiendo transcurrido más de treinta años desde su «descubrimiento», la corriente de Humboldt, y los efectos que producía sobre el litoral, todavía seguían sin ser cabalmente estudiados. También, que el capitán vislumbraba por la experiencia la influencia que la corriente tenía en el clima del litoral occidental sudamericano y, tal vez, en razón de su constatación, que al momento de navegar en torno de las Galápagos se experimentaba un desplazamiento de aguas frías hacia el Ecuador, hoy conocido como fenómeno de la Niña.

\section{La hidrografía nacional}

\section{Los primeros levantamientos}

En el contexto del reconocimiento de las costas del Pacífico sur que se venía desarrollando desde el siglo XVIII a través de numerosas comisiones organizadas por los imperios europeos, y teniendo en cuenta algunos de los problemas esenciales de la navegación a vela como era el de la determinación de las rutas a seguir para efectuar la travesía del modo más breve y seguro, fue que la Armada de Chile inició sus trabajos de exploración geográfica. No fue hasta la década de 1830 cuando la Armada de Chile realizó el primer reconocimiento hidrográfico del litoral nacional. Hasta entonces, la Guerra de Independencia, la organización de la República, la falta de recursos y de personal calificado, y la urgencia de atender otras necesidades más apremiantes, entre otros factores, impidieron al Estado ocuparse de una tarea que en lo que dice relación con la superficie continental se había iniciado formalmente en 1830 cuando el naturalista Claudio Gay fue contratado por el gobierno para realizar un viaje científico por todo el territorio nacional. ${ }^{20}$

19 Fitz-Roy, 2013, 431-432.

20 Véase Sagredo Baeza, 2010b. 
En 1834, mientras cumplía con la misión de trasladar una guarnición militar desde Valparaíso a Valdivia, el comandante de marina Roberto Simpson reconoció la desembocadura del río Bueno en la costa valdiviana y ordenó levantar un plano de ella al teniente Felipe Solo de Zaldívar. La exploración, como la representación que resultó de ella, se tiene como la primera expresión de la hidrografía nacional. La intención de Simpson habría sido colaborar con las autoridades, explorando el río Bueno, una de las posibles rutas de entrada a una región que se apreciaba con gran potencial económico, como efectivamente se comprobó más adelante, cuando comenzó a ser explotada por los colonos de origen alemán llegados a comienzos de la década de 1850 .

Poco se sabe de las condiciones en que se cumplió el levantamiento, quedando como testimonio de su realización el plano con la representación de la ensenada y embocadura del río Bueno, en el que se incluyen instrucciones náuticas que suplían el derrotero. ${ }^{21}$ Realizado a mano alzada, el contorno de la costa sólo ofrece detalles en el saco mismo de la ensenada, mientras que las coordenadas están indicadas al grado, minutos y fracciones.

Debieron pasar siete años, con una guerra internacional de por medio, contra la Confederación Perú-Boliviana, para que se reanudaran las tareas hidrográficas. Éstas fueron continuadas por marinos como Domingo Salamanca y Leoncio Señoret, quienes levantaron pequeños tramos del extenso litoral chileno, todos ellos situados al norte de Chiloé, como los de la isla Mocha, frente a las costas de la Araucanía, y Constitución, en la orilla sur de la desembocadura del río Maule, realizados en 1841 y 1844 respectivamente. ${ }^{22}$ Dichos trabajos, en ocasiones acompañados de breves descripciones, fueron seguidos por otras comisiones encabezadas por Señoret, a quien, entre 1844 y 1869 , se le encargaron distintos levantamientos y exploraciones de las costas de la Araucanía y de los ríos Maule, Lebu y Toltén.

No sobra señalar que los trabajos hidrográficos se complementan con los que entonces, 1830 a 1875, desarrollaron el naturalista Claudio Gay, y más tarde el geógrafo Amado Pissis, a quienes se les había encargado la confección de mapas de Chile y sus provincias y un atlas general del terri-

21 Véanse Cordovez M., 1937, 23-25, y el sitio web del Servicio Hidrográfico y Oceanográfico de la Armada de Chile, SHOA, en el que se reproduce el mencionado plano. En la que el SHOA llama «Reseña histórica», se encuentra parte de la cartografía generada por las exploraciones hidrográficas realizadas en el siglo XIX, véase, http://www.shoa.cl/pagnueva/resena_historica.html.

22 Véase Couyoumdjian, 2013. 


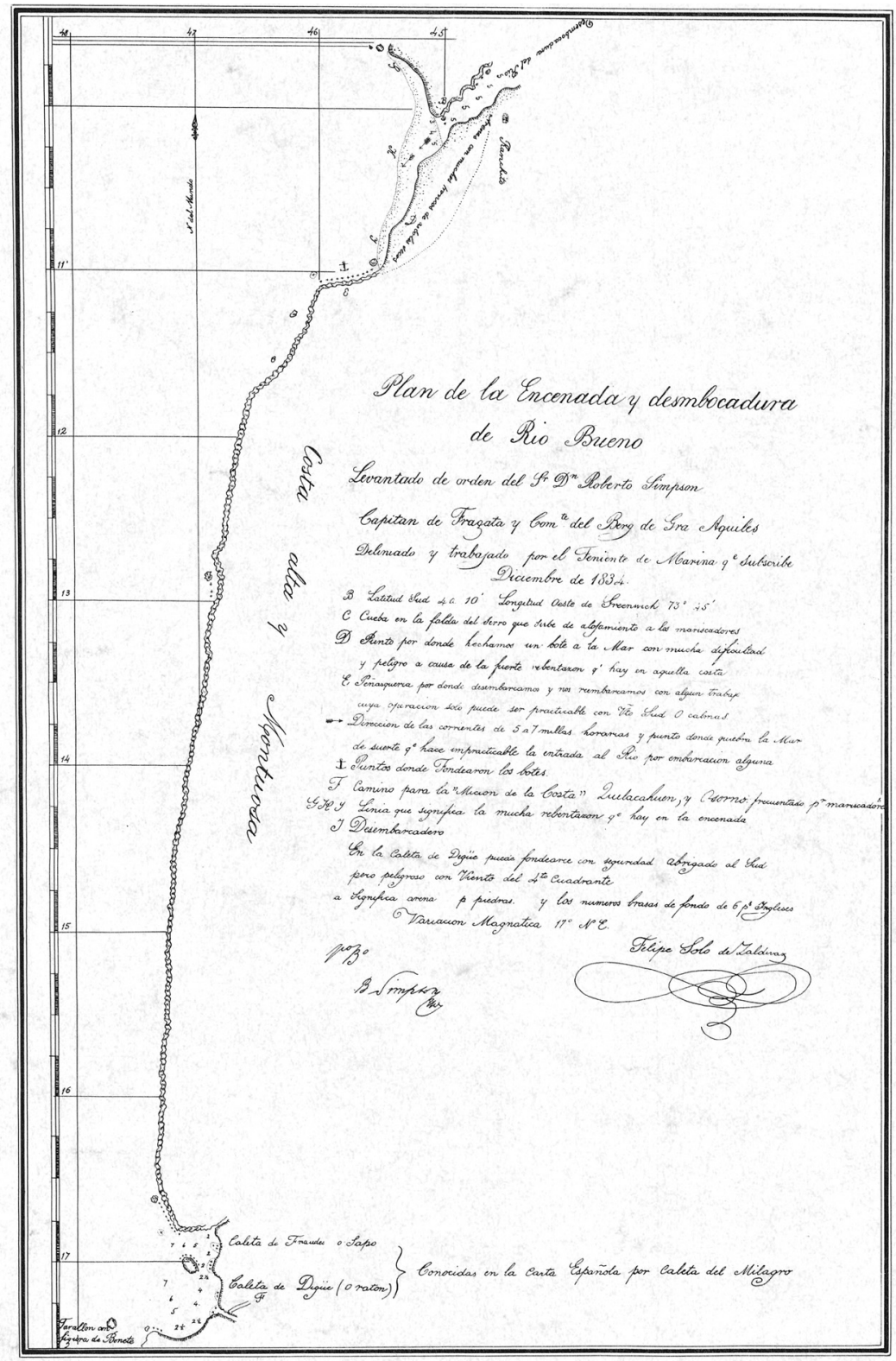

Plano de la ensenada y desembocadura del río Bueno levantado en 1834. Se considera la primera expresión de los reconocimientos hidrográficos nacionales. 
torio. La necesidad de conocer cabalmente el espacio de la república, identificar sus recursos naturales y ejercer soberanía efectiva sobre ellos, explican los afanes del Estado chileno por explorar y representar su territorio y litoral.

Estos esfuerzos se materializaron en expediciones terrestres, como la encargada al naturalista Rodulfo A. Philippi al desierto de Atacama en 1853 , la que fue complementada desde el mar por una nave comandada por el capitán Manuel Escala, a quien se le comisionó recorrer las costas de Atacama reconociendo y levantando planos de las bahías existentes, entre ellas las de Mejillones, Chañaral y Taltal. ${ }^{23}$ Las mismas que años después serían utilizadas para sacar los minerales que comenzarían a explotarse en medio del desierto, y cuyos levantamientos servirían también para orientar a las tropas chilenas que ocuparían la provincia de Antofagasta durante la Guerra del Pacífico.

En lo que respecta al mar y costas, la tarea de reconocerlos, describirlos y cartografiarlos no fue sistemática, como sí lo fue la que los naturalistas desarrollaron en el territorio nacional, pasando años sin que se promovieran expediciones navales. Las comisiones hidrográficas iniciales se concentraron esencialmente en el reconocimiento del litoral entre Atacama y Aconcagua, como el de las caletas de los Vilos y los Choros en 1854; en el de los cursos y desembocaduras de ríos en la zona centro y sur, como la ya mencionada del Bueno, y la del río Maullín en 1856 y 1857; y en la búsqueda de una vía de comunicación entre el archipiélago de los Chonos y el golfo de Penas en la costa desmembrada de Chile austral en 1857. Esta comisión, encabezada por el teniente de la marina Francisco Hudson, dio el nombre de canal Moraleda al brazo de mar existente entre el continente y el archipiélago de Chonos al sur de la isla de Chiloé; descartó un paso entre este canal y el golfo de Penas; y recomendó iniciar la exploración sistemática y los levantamientos hidrográficos de la zona. En la comisión, además, participó un joven guardiamarina, Francisco Vidal Gormaz, quien entonces inició una carrera que lo llevaría a convertirse en el principal hidrógrafo chileno.

En estos años también se inició la participación de Luis Pomar en las tareas hidrográficas. Primero, en 1862, al servicio de Señoret, levantando el plano de la caleta Quidico situada frente a la isla Mocha, y más tarde en

23 Véase Philippi, 2008. Otro de los objetivos de Escala fue verificar la exactitud de la cartografía levantada por Robert Fitz-Roy, la que según los marinos chilenos era muy incompleta e inexacta. 
reconocimientos en el norte y centro del territorio hasta la costa del Golfo de Arauco. Las costas de la Araucanía y de las provincias de Antofagasta, Valparaíso, Santiago, Aconcagua y Concepción, es decir de la zona central y más poblada de Chile, fueron objeto preferente de sus minuciosos estudios, planos, geografías náuticas y derroteros. Todos desarrollados luego de la Guerra del Pacífico contra Perú y Bolivia, y que lo llevaron también a Subdirector y director de la Oficina Hidrográfica en diferentes oportunidades, la última entre 1902 y 1904.

El reconocimiento de los ríos, lagos, desembocaduras y otra serie de accidentes importantes para la navegación, el comercio y la integración de territorios a la efectiva soberanía del Estado, se puede explicar en la necesidad de apreciar los cursos fluviales como posibles vías de cabotaje, mientras que la existencia de un paso entre los Chonos y el golfo de Penas facilitaría y aliviaría la penosa navegación de las naves que transitaban por aquella azarosa región del Pacífico austral. De existir el buscado paso, los barcos podrían hacer su derrota por aguas interiores, evitando así el océano abierto y su constante mar gruesa y temporales.

Los progresivos reconocimientos de diversos puntos de la costa chilena, al parecer, seleccionados de acuerdo con la explotación de los recursos nacionales y la necesidad de integrar territorios a la soberanía nacional, explican que en la década de 1860, se exploraron la costa carbonífera de Arauco y se reconociera la barra del río Queule y remontara el río Toltén, como medio de controlar la llamada Baja Frontera a través de la fundación de poblados. En todas estas comisiones participó Vidal Gormaz. También lo hizo en la comisión exploradora de los ríos Valdivia, Cruces y CalleCalle entre 1868 y $1869 .{ }^{24}$

Habiéndose acumulado hasta 1866 un gran número de noticias, reconocimientos y levantamientos de las costas como resultado de las diversas comisiones emprendidas por la Marina, se decidió publicar todos los trabajos hidrográficos realizados hasta entonces bajo el epígrafe de Apuntes hidrográficos sobre la costa de Chile, acompañados de algunos planos levantados por los oficiales de la Armada de la república. No sólo una fuente esencial para el estudio de una tarea hasta ahora prácticamente olvidada; además, en su época, un estímulo para seguir explorando el litoral en aquellas zonas todavía desconocidas o parcialmente conocidas por los marinos.

24 Véase Couyoumdjian, 2013. 
Confundidas con las comisiones de Vidal Gormaz, el Estado dispuso a partir de entonces, y durante gran parte de la década de 1870 hasta 1879 , el sucesivo reconocimiento de la costa comprendida entre la rada de los Vilos y el río Choapa; entre el río Valdivia y el morro Bonifacio y el río Maullín; del litoral entre Corral y Reloncaví; la exploración de la costa entre Llanquihue y el archipiélago de Chiloé; la del seno de Reloncaví, el lago Llanquihue y el río Puelo; la de la costa de Colchagua y Curicó; y el reconocimiento del río Maullín.

Muestra del interés por el cabal conocimiento de sus costas, en 1874 el gobierno chileno había dispuesto la creación de la Oficina Hidrográfica que, anexa al Ministerio de Marina, tuvo como primer director al entonces ya reconocido hidrógrafo Francisco Vidal Gormaz. La creación de la Oficina Hidrográfica de Chile fue la materialización institucional de una realidad que, con altibajos, venía desarrollándose desde 1834, esto es la poco sistemática pero persistente exploración del litoral chileno, que no por parcial dejaba de ser efectiva respecto de los puntos reconocidos y representados cartográficamente. El desarrollo marítimo, estrechamente relacionado con el comercio y la navegación a vapor por las costas del Pacífico sur y austral, fue el objetivo general que se tuvo al crearla al amparo del Ministerio de Marina. La recopilación de información sobre la geografía náutica del litoral en vistas a un completo conocimiento de él y a la confección de un derrotero general de las costa de Chile; la organización de la estadística de los siniestros marítimos que ocurriesen en las costas y aguas del país; y el estudio de la física del mar de Chile, es decir la obtención de noticias meteorológicas e hidrográficas, fueron algunas de las primeras tareas que se impuso su director. Y esto, siempre, como señaló Vidal Gormaz, teniendo en vista que los estudios no pueden ser sólo hidrográficos, pues los adelantos de la época exigían que junto a estos los marinos realizaran observaciones geográficas, físicas y de historia natural. ${ }^{25}$

Entre las primeras iniciativas de la nueva repartición estuvo la exploración del litoral boliviano, con la excusa de aclarar algunas dudas existentes en los derroteros modernos, como también la recopilación de noticias sobre los canales de Magallanes, la Patagonia y Chiloé, las costas entre el río Mataquito y la bahía de Concepción, entre Matancilla y Valparaíso, des-

25 Véase el texto de Francisco Vidal Gormaz con que se abre el primer número del Anuario Hidrográfico de la Marina de Chile que la Oficina Hidrográfica comenzó a publicar a partir de 1875 , Santiago, 1, 1875, IX. 
de este puerto hasta Horcón, las islas San Félix y San Ambrosio y las islas y arrecifes esporádicos frente a las costas del país. ${ }^{26}$ Continuando y sistematizando la tarea de recopilar información sobre prácticamente todo el litoral occidental sudamericano al sur del paralelo $27^{\circ} \mathrm{S}$. En 1876 se ordenó el reconocimiento de la costa de la provincia de Atacama desde Caldera, hasta Antofagasta, en los $23^{\circ} 38^{\prime} \mathrm{S}$, entonces ya un territorio en disputa con Bolivia. También se reconocieron tramos del litoral al norte de Valparaíso y otros de la zona sur y austral, entre ellos los canales de la Patagonia, intentando así completar la hidrografía de Chile al norte del archipiélago de Chiloé. Respecto del litoral situado al sur de Chiloé, se dispuso también su reconocimiento, entre otras razones, por los numerosos naufragios que en ella se producían. Entonces se pretendió completar los trabajos hidrográficos que el capitán Enrique Simpson había emprendido entre 1870 y 1874, que a su vez tenían antecedentes en las exploraciones de Buenaventura Martínez en el estrecho de Magallanes en 1848, y en las Francisco Hudson entre 1855 y 1857 entre la isla de Chiloé y Magallanes. ${ }^{27}$

\section{Exploración de los archipiélagos australes}

Entre las comisiones enviadas al Pacífico austral por la marina chilena, los cuatro viajes a la costa occidental de la Patagonia que realizó entre 1870 y 1874 el capitán de fragata Enrique Simpson, fueron las más sistemáticas y las que ofrecen algunas de las características esenciales de los afanes hidrográficos desarrollados por el país a lo largo del siglo XIX.

Las de Simpson, como la mayor parte de las comisiones de exploración del litoral nacional, se encuentran consignadas en informes epistolares con la crónica de las travesías emprendidas, sus avatares y sucesos más sobresalientes, en las que se narran sus incidencias diarias y se da cuenta de las materias solicitadas por el Ministerio de Marina, es decir: rutas, estado de puertos, canales, flora, fauna, habitantes, geografía, mareas y la situación meteorológica de las regiones exploradas. También ofrece la realidad material de estas empresas, la forma en que se organizaban, equipamiento, instrumental, calificación del personal y trabajos propios de las mismas. Por último, muestran algunas de las preocupaciones esenciales del Estado

26 Véase Anu. Hidro., 1, Santiago, 1875, VIII-IX.

27 Cordovez M., 1937, 26-27. 
nacional, esto es, el reconocimiento de parajes prácticamente desconocidos, pero también, y en particular en la zona comprendida entre los 44 y 46 grados de latitud sur aproximadamente, la búsqueda de pasos que comunicaran la Patagonia occidental con la oriental, elemento y antecedente esencial en la disputa por la región que mantenían desde la década de 1840 Chile y Argentina.

Hasta el momento de la exploración de Simpson, y como ocurría para gran parte del litoral chileno, el conocimiento existente sobre el área que se extendía entre las islas Guaitecas y el golfo de Penas era muy limitado y parcial, y en todo caso absolutamente insuficiente en relación con la necesidad de conocer acabadamente la geografía marítima de la región. Este se componía de relaciones de los viajes de misioneros españoles y de los reconocimientos de marinos como José Moraleda y Robert Fitz-Roy, todos básicos, parciales, imprecisos en muchos aspectos y, por último, preparados con otros objetivos. Para el Estado de Chile, la inexistencia de noticias ciertas sobre una región que como la Patagonia y Tierra del Fuego se encontraban en controversia, resultaba intolerable ante la necesidad de defender los derechos que el país creía tener sobre estos espacios. Entonces no sólo el saber sobre el litoral de la Patagonia era insuficiente, sobre todo faltaba información relativa a las zonas ultracordilleranas de la llamada Patagonia central, las cuales se creía encerraban riquezas naturales y eran propicias para la colonización. La expedición del alguna vez comandante de la Marina Británica George Ch. Munster, que en 1870 había recorrido la Patagonia interior desde el estrecho de Magallanes hasta Carmen Patagones, en las cercanías de la desembocadura del Río Negro en el Atlántico, sin duda alentaron los afanes chilenos por explorar la región. ${ }^{28}$

Las órdenes que Simpson recibió del Ministerio de Marina para su primera comisión fueron claras: reconocer la costa occidental de la Patagonia; explorar prolijamente los ríos, en especial el Aysén, y las llamadas internaciones del mar entre los $44 \mathrm{y} 46^{\circ}$ grados de latitud en búsqueda de un paso para la Patagonia oriental; formar planos de las regiones exploradas en los que se fijen los puertos y caletas que puedan abrigar naves; sondear e identificar los accidentes interesantes a la navegación; formar croquis de los terrenos adyacentes a las costas; y recoger muestras de espe-

28 Véase el «Prólogo» de Mateo Martinic a la edición de los textos de Enrique M. Simpson publicados con el título de Viajes de exploración por los archipiélagos australes. 
cies animales y vegetales y de minerales. Expresión de los intereses nacionales presentes en la comisión hidrográfica que se encargó al comandante Simpson, es el hecho que se le advirtió que en sus informes prestara particular atención en «hacer notar las depresiones de la cordillera y la clase de terrenos planos que visite». ${ }^{29} \mathrm{La}$ trascendencia de este aspecto se refleja también en que en el informe de su primera exploración, fechado en junio de 1870 y dirigido al Ministro de Marina, Enrique Simpson escribió, en el primer párrafo: «Tengo el honor de poner en conocimiento de su señoría el resultado de mi expedición a la costa occidental de la Patagonia por dentro del archipiélago de Chonos, entre los límites de $44^{\circ}$ y $46^{\circ}$ latitud $S$ en busca de un paso por la Cordillera hacia el interior». ${ }^{30}$ Esto explica también que en sus cuatro viajes de exploración Simpson y sus hombres hayan combinado la navegación, propia de los marinos e hidrógrafos, con las «travesías por tierra», en particular hacia el oriente, subiendo y bajando por entre los Andes.

Como otros antes que él, Simpson también se sirvió de las relaciones y cartografía de quienes los habían antecedido en el reconocimiento de las costas del Pacífico austral, en particular Moraleda y Fitz-Roy. Sin embargo, ya en su primera salida concluyó que ni las representaciones de Moraleda ni las del capitán inglés tenían utilidad al sur de Melinka, es decir desde la entrada en adelante del archipiélago de Chonos pues, argumenta,

Fitz-Roy sólo levantó el plano hasta Melinka, y el resto no pasa de ser un croquis inexacto del piloto de la marina española. Sirviendo sólo para dar una idea del arrumbamiento del canal principal que corre aproximadamente de norte a sur (el llamado canal Moraleda), siendo hasta las latitudes tan erradas, que nos es casi imposible fijar en él con precisión los puntos donde las circunstancias no nos permitieron hacer observaciones astronómicas. ${ }^{31}$

En otra forma de relación con quienes lo habían precedido en el reconocimiento de la zona, Simpson logró el concurso de un «consumado práctico» de la zona. Juan Yates, el mismo que había acompañado a Robert Fitz-Roy casi cuarenta años antes. Muestra a su vez que mucho de lo que se tiene por reconocimiento hidrográfico imperial o nacional, en definitiva,

29 Simpson, 2011, 22.

30 Ibidem, 23.

31 Ibidem, 25. 
es también consecuencia del conocimiento local, de la práctica que los habitantes de los archipiélagos australes tienen, por ser la navegación entre ellos una parte esencial de su forma de vida. Considerando las noticias que William H. Hudson había obtenido en 1857 durante su expedición por la Patagonia, que a su vez también había recurrido a Moraleda, el marino chileno inició sus trabajos hidrográficos por los canales septentrionales de las Guaitecas, teniendo siempre como referencia los trabajos de Fitz-Roy y, en especial, la posibilidad de encontrar una «ensenada profunda, no reconocida, donde desemboca entre llanuras un río caudaloso de agua blanquizca», que ofreciera la posibilidad de un paso transcordillerano..$^{32}$

El relato de Simpson muestra las grandes esperanzas que abrigaba de, en medio de sus reconocimientos de esteros, ríos y comarcas aledaños al canal Moraleda, en particular del Aysén, como un siglo antes Moraleda, «en medio de inmensas montañas coronadas de nieves perpetuas», haberse adentrado lo suficiente hacia el oriente como para haber «salvado ya la cordillera y encontrado el paso tan deseado». Vana ilusión pues, como escribió, pronto pudo apreciar que «las montañas aun continuaban al este, hasta donde alcanzaba la vista». Dejando para las posteriores comisiones el cruce de los Andes, pues los obstáculos existentes en los ríos que bajaban hacia el oeste se lo impidieron la primera vez.

La cuidadosa exploración de los canales interiores y de sus costas, como el levantamiento de sus respectivos planos, ocupó la mayor parte del tiempo de Simpson y sus hombres en sus sucesivas comisiones entre las Guaitecas y Chonos, preparando así una cartografía nacional mucho más exacta y detallada que la imperial que Moraleda y Fitz-Roy habían elaborado. Contribuyó a la calidad de las representaciones, sobre todo en comparación con la obra de Moraleda, el instrumental —eclímetro, círculo de reflexión, teodolito, higrómetro, anteojo micrométrico de Rochon, horizontes artificiales, transportador metálico y cronómetros- con que contaron los marinos chilenos pues, como se sabe, en la zona son frecuentes los temporales, y las lluvias y neblinas casi incesantes, «hasta el punto de no vislumbrarse el sol por semanas enteras, haciendo difusas las observaciones astronómicas». Lo que para Simpson explicaba «la inexactitud de las cartas de Moraleda que contienen, advirtió, incluso en las latitudes, grandes errores»..$^{33}$

32 Ibidem, 28

33 Ibidem, 38. 
DE LA HIDROGRAFÍA IMPERIAL A LA HIDROGRAFÍA NACIONAL

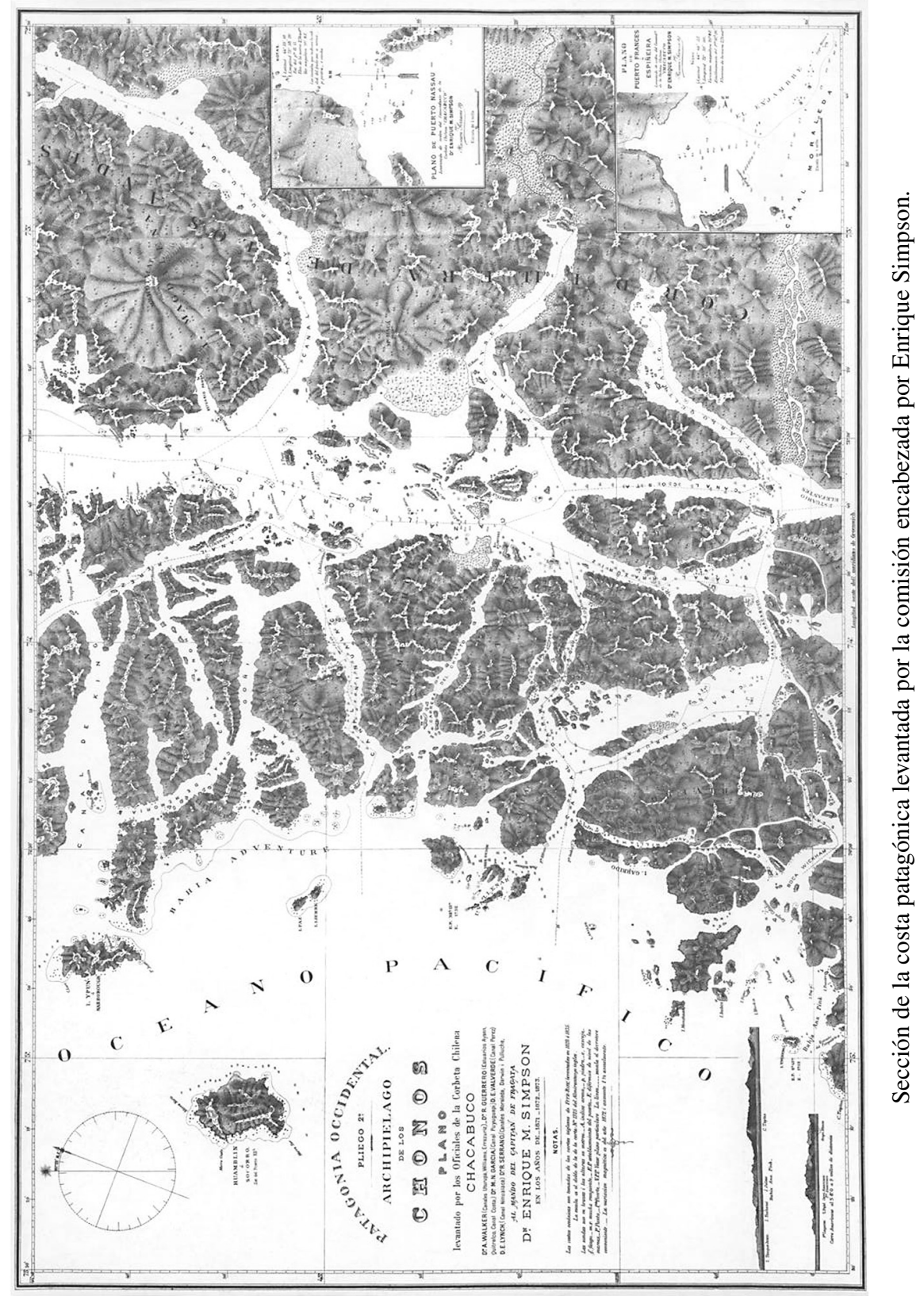


Señaladas las diferencias entre las mareas del mar interior, entre la costa de la Patagonia y las Guaitecas y Chonos, y el exterior, al oeste de los archipiélagos, como las características de la geología de la región, su clima, fauna y flora, Simpson concluyó su primera excursión exponiendo que había comprobado que las aguas interiores de los archipiélagos eran seguras para los vapores; que había descubierto cuatro puertos nuevos y levantado planos que asegurarían la navegación de los veleros que transportaban madera en la zona; explorado el estero Aysén, rectificando su posición que padecía un error de 18 millas en latitud al norte de la verdadera; reconocido un valle fértil al fondo del río Aysén, penetrando hasta una longitud $72^{\circ} 33^{\prime}$ Oeste, aunque sin dar fin al valle; y, esencial para sus objetivos, «dado a conocer la posibilidad de que exista un paso por agua a través de la cordillera, al sur de Aysén, pues, hasta donde ha podido verse, deja de ser una cadena continuada en este punto, con notable depresión». ${ }^{34}$ También reconoció que todavía quedaban pendientes el levantamiento exacto de las costas interiores de los archipiélagos de Chonos y Guaitecas entre Melinka y la península de Taitao, así como una sección de la costa de la Patagonia hasta Taitao, todos indispensables para facilitar la navegación de los veleros; por último, que los canales al sur del Aysén eran enteramente desconocidos, siendo éstos su prioridad en la siguiente comisión.

Su segunda excursión, que se desenvolvió entre diciembre de 1870 y mayo de 1871, fue concebida entonces como una continuación de los trabajos de Fitz-Roy, por el área que abarcaría, esto es, al sur del río Aysén y hasta la laguna de San Rafael, con especial énfasis en la búsqueda de un paso entre el canal Moraleda y el golfo de Penas a través de la península de Tres Montes. También se le ordenó proseguir la exploración del Aysén hacia el Oriente hasta donde fuera posible, «a fin de reconocer los ríos y lagunas que pudieran aprovecharse para una comunicación interoceánica». Retomado de este modo la búsqueda que alguna vez había llevado a la zona a José Moraleda quién, como sabemos, había desechado la existencia de dicho paso. Muestra del interés oficial por la región, en su segunda salida Simpson embarcó un sujeto encargado de estudiar la historia natural.

Avanzando esta vez más allá del canal Moraleda hacia el sur, Simpson y sus hombres accedieron al canal Costa y de ahí al estero Elefantes en su búsqueda de la laguna San Rafael, explorando y cartografiando el litoral, adentrándose en los ríos existentes en la Patagonia, siempre «con la espe-

34 Ibidem, 44 
ranza que atravesase la cordillera». Evidencias, como rastros de ciervos no vistos hasta entonces, que los llevaban a pensar que venían desde la Patagonia oriental, alentaron los reconocimientos de los marinos chilenos. Por ejemplo, hacia el interior del estuario Quitralco para, luego de una esforzada marcha hasta topar con un ventisquero y concluir, convencido, como escribe Simpson, «de que no había paso practicable por este valle». ${ }^{35}$ Tampoco encontró entonces, porque no existe, el paso hacia el sur, hasta el golfo de Penas, por el itsmo de Ofqui, más allá de la laguna de San Rafael.

Simpson retomó entonces la exploración del río Aysén, ahora «desesperado de no haber encontrado al sur río caudaloso alguno que prometiese fácil comunicación con la Patagonia oriental a través de los Andes». ${ }^{36}$ Ahora siguiendo hasta sus fuentes, en la ultracordillera, por los únicos brazos que antes no había explorado, con la ilusión de poder construir un camino carretero por sus márgenes pues, por lo torrentoso, es imposible como vía de comunicación. Después de internarse poco más de 200 kilómetros hacia el este desde el canal Moraleda, dedujo más tarde encontrarse al otro lado de los Andes, luego de haber atravesado no menos de 88 kilómetros (55 millas) de cordillera; entre otras razones por no experimentar los temporales que arreciaron en la costa al mismo tiempo que él se hallaba en las que nombra «llanuras del oriente», dejando para una próxima campaña el reconocimiento «de los terrenos de esa región que deben ser muy fértiles».

Resultado de su segunda campaña fueron el levantamiento de planos con sondas de 256 millas — poco más de 411 kilómetros — de canales y estuarios, respecto de los cuales no existía ni siquiera un precario croquis; la apertura a la navegación de dos nuevas vías de comunicación con las aguas interiores del archipiélago y tierra firme; la definición del itsmo de Ofqui por el norte; el redescubrimiento de la laguna San Rafael; y, por último pero muy relevante, el «haber atravesado la cordillera de los Andes hasta su última garganta, por agua, comprobando que el río Aysén nace en la Patagonia oriental, y dando a conocer la facilidad de construir un camino carretero o ferrocarril hasta ese territorio». ${ }^{37}$ Pendientes quedaron una sección del plano del canal Moraleda y, sobre todo, el resto de los canales interiores del archipiélago. Tareas que se emprendieron en las dos siguientes comisiones.

35 Ibidem, 60-61.

36 Ibidem, 77.

37 Ibidem, 85-86. 
En el tercer viaje entre octubre de 1871 y junio de 1872 , los trabajos se iniciaron con la expedición al río Aysén, en la Patagonia, en la búsqueda del ansiado camino por la cordillera. Finalmente, a fines de diciembre y a la altura del paralelo $45^{\circ} 25^{\prime}$, Simpson y sus hombres lograron pasar la gran cadena andina y situarse en su falda oriental; entonces calcularon que habían atravesado «más de cien millas de cordillera». Fue la culminación de tres años de afanes destinados a cumplir con un propósito esencial para las aspiraciones soberanas del Estado chileno sobre la región. A continuación, los marinos emprendieron la expedición al interior de la península de Taitao, siempre con la ilusión de hallar ahí un paso hacia el golfo de Penas.

El reconocimiento de la zona hizo posible el levantamiento de planos y diversas observaciones, hasta que Simpson no tuvo más remedio que escribir en su informe: «concluyó toda esperanza de encontrar paso al golfo de Tres Montes, al sur de Taitao, siendo toda esta costa limitada por una barrera de altas montañas nevadas que parecen llegar hasta el océano formando el cabo Tres Montes». ${ }^{38}$ Los reconocimientos de ríos, canales y estuarios en medio del archipiélago de Chonos, así como el inicio del levantamiento del plano del canal Moraleda y el de los principales canales de la zona, completaron una comisión hidrográfica que, nunca dejó de estar atenta a la búsqueda de pasos transcordilleranos, como lo demuestra el que comprobaran la existencia de otro por el valle Huemules, en los $46^{\circ} 6^{\prime} \mathrm{S}$.

En su última salida, entre octubre de 1872 y mayo de 1873, los marinos comandados por Enrique Simpson completaron el plano del Canal Moraleda; delinearon el grupo de islas de las Guaitecas; estudiaron el puerto de Melinka, el principal de la región; reconocieron el río Cisnes; y exploraron canales en búsqueda de puertos convenientes para refugio de las naves averiadas o sotaventadas sobre la costa. Un ejemplo es el hallazgo de un «puerto magnífico» en la islas Rhone: «tiene fondo de arena, con siete $(12,8 \mathrm{~m})$ a dieciocho brazas de profundidad, es abrigado contra todos los vientos reinantes, y fácil de tomar y dejar. Contiene además leña y agua en abundancia». ${ }^{39}$

En las cuatro estaciones, que en total suman quince meses de exploración entre 1870 y 1873, los marinos comandados por Enrique Simpson reconocieron el archipiélago de Chonos, la península de Taitao y la Patagonia occidental. Su trabajo hizo posible reconocer y preparar planos

38 Ibidem, 121.

39 Ibidem, 175. 
de toda la comarca, complementando, sostuvieron entonces, el levantamiento de las costas oceánicas que Fitz-Roy había realizado y que tanta fama le valió. De hecho, para Simpson, su trabajo, era el corolario del realizado por el inglés. ${ }^{40}$ La ponderación de su trabajo como hidrógrafo no impidió al marino chileno concentrarse en la Patagonia y en las posibilidades que sus descubrimientos implicaban para las aspiraciones del país. Fue así como preparó las que llamó consideraciones sobre la Patagonia occidental, pero que también aludían a la oriental. En una perspectiva estrictamente geográfica, escribió que la cordillera misma en la zona no es sino otro archipiélago de montañas en escala mayor, separados por agua, rematando los estuarios o brazos de mar que se internan desde el oeste, en valles que comunican con la Patagonia oriental, como ocurre en el Aysén y Huemules que exploró.

En relación con la Patagonia oriental, antes de conocerla, y siguiendo a viajeros que como Musters lo habían precedido, escribe que se trata de una región estéril en la sección adyacente al Atlántico; mientras que en las cercanías de los Andes es más fértil. En su concepto esa faja pertenece, por la influencia que recibe de los vientos del oeste, «más bien al Pacífico que al Atlántico, siendo más accesible por este lado, de modo que parece que la naturaleza misma prescribiese la soberanía de Chile». ${ }^{41}$ Para sostener sus planteamientos Simpson agrega que la Patagonia es un país montañoso y quebrado, siendo su parte oriental «de carácter totalmente distinto de las pampas de Buenos Aires, de las cuales muchos, erróneamente, han creído su continuación». Consciente de la importancia de los Andes en la definición de la frontera chileno-argentina, a la vez que adelantando las controversias geográficas que sobrevendrían, sostuvo que al parecer el nivel de los terrenos bajos sube desde el Pacífico hasta «llegar a una sierra de orden secundario, más allá del Collar de montañas que hasta aquí se ha denominado Cordillera de los Andes, y de la cual es sólo la continuación austral». Esa sierra secundaria, o lomo, como la llama, constituye para Simpson «la verdadera división de las aguas». Siendo esta la razón que se encuentren ríos como el Aysén que, «proviniendo del otro lado, atraviesan por completo el Collar de los Andes».

Aludiendo directamente a la disputa existente entre Argentina y Chile por la Patagonia, en particular la sección entre los ríos Santa Cruz y Negro,

40 Ibidem, 209.

41 Ibidem, 137-138. 
afirma que sólo la mitad occidental es fértil, pues la otra es «completamente estéril», y que a la primera es «mucho más accesible desde el Pacífico que desde el Atlántico». La razón, porque para alcanzarla desde allá hay que atravesar inmensos desiertos, casi sin agua, mientras que comunica con los estuarios y canales del oeste. Atrevido, más allá de lo que se le había solicitado, reflejando tal vez una opinión extendida entre los marinos chilenos, concluye sus consideraciones afirmando: «Por esta razón, soy de opinión que, al tratarse de una división de estas tierras, se fije la línea divisoria entre los ríos Santa Cruz y Negro, en el meridiano medio, es decir, longitud $70^{\circ} \mathrm{O}$ de Greenwich. De este modo, ambas repúblicas tendrían lo que mejor podrían atender. Nosotros no necesitaríamos enviar nuestros buques a tan largas distancias y ellos conservarían las salinas que tanto necesitan para su industria». ${ }^{42}$ Una frase que en lo que se relaciona con las aspiraciones chilenas resulta del todo inconveniente, pues reconoce que los espacios allende los Andes eran ajenos, distantes, de Chile, como por lo demás siempre lo habían sido.

Luego de sus comisiones por la región de Aysén, Simpson exploró entre 1874 y 1875 los canales occidentales de la Patagonia, los del territorio de Magallanes y, finalmente, el río Santa Cruz en la Patagonia oriental. En algunas de estas tareas, como en las desarrolladas antes en las Guaitecas y Chonos, lo acompañó Ramón Serrano Montaner quien, primero como guardiamarina, fue ascendiendo en el escalafón naval al ritmo de sus comisiones hidrográficas. A este dotado marino se deben algunos importantes levantamientos como el canal Darwin y otros en Tierra del Fuego e isla Dawson en los alrededores de Tierra del Fuego, todos realizados entre 1872 y 1879. Particular relevancia tuvieron en esa época sus exploraciones y reconocimientos de los territorios en litigio con la Argentina. A través de ellos ofreció información de primera fuente sobre áreas que otros antes habían calificado de pampas estériles, vegetación raquítica e inhospitalarios ambientes para la población.

Concluida la Guerra del Pacífico, en la que participó activamente, y luego de servir como Subdirector de la Escuela Naval y luego de la Oficina Hidrográfica, Serrano volvió a las comisiones de reconocimiento geográfico, realizando a partir de 1888 levantamientos en la zona inmediata al paralelo $52^{\circ} \mathrm{S}$ y los meridianos $71^{\circ}$ y $72^{\circ} \mathrm{O}$, es decir en los extensos y poco conocidos brazos de mar que, como el seno de Última Esperanza, el seno

42 Ibidem, 215. 


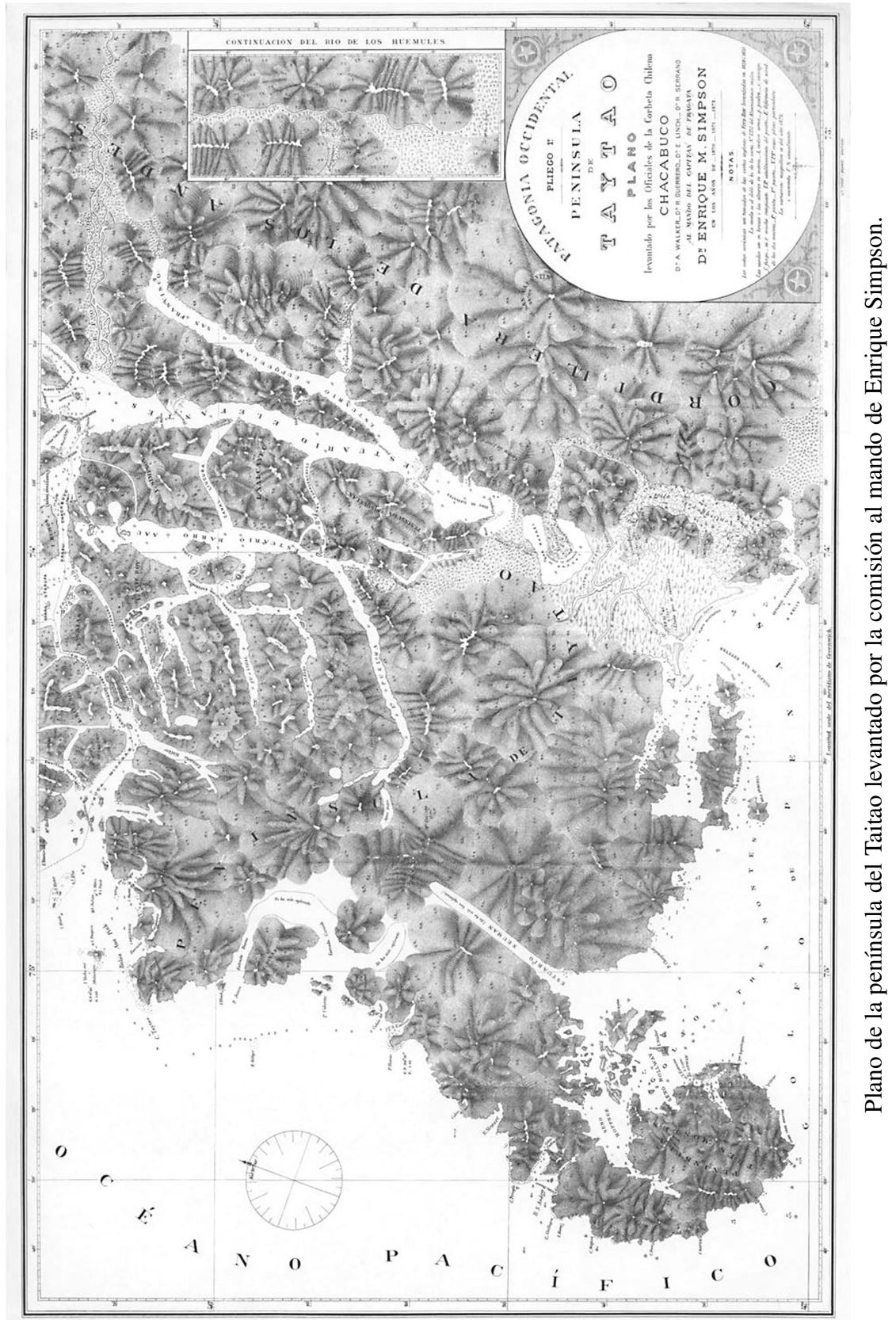


Skyring, el paso Fitz-Roy y el seno de Otway, forman parte de la enmarañada geografía de los canales australes.

Muestra de las capacidades, conocimientos, experiencia, cualidades y virtudes para apreciar la realidad geográfica que se atribuían a Serrano Montaner, en 1890 el gobierno lo nombró Primer Ayudante de la Comisión de Límites con la república Argentina. Tal vez la culminación, a través de este oficial, de los servicios que la Armada de Chile había prestado a lo largo del siglo XIX en el reconocimiento del litoral nacional y, sobre todo desde 1870, en el sistemático levantamiento hidrográfico y exploración geográfica de las regiones en disputa con Argentina. Esta destinación, junto a la publicación en 1891 de su renombrado Derrotero del Estrecho de Magallanes, de la Tierra del Fuego y de los canales de la Patagonia, no sólo resumen la obra de casi medio siglo de trabajos hidrográficos, también completaban el reconocimiento del litoral iniciado de 1834 con el levantamiento del plano de la desembocadura del río Bueno.

\section{Otras exploraciones y publicaciones hidrográficas}

El mismo año que Roberto Simpson culminaba su trabajo en los archipiélagos australes, la Oficina Hidrográfica inició un programa de exploraciones destinado a estudiar el litoral boliviano para resolver algunas dudas en los derroteros. Mientras tanto se continuó reuniendo información sobre los canales australes y diversos puntos de las costas central del país; incluso de las islas Esporádicas. Dos años más tarde, en 1876, se ordenó la exploración del litoral de la provincia de Atacama, ahora, entre Antofagasta y Caldera, siempre, como escribió Vidal Gormaz, con la confianza de que en «breve tendremos un conocimiento completo de la hidrografía de la parte continental de Chile, al norte de Chiloé».43

La Guerra del Pacífico, desatada en 1879, obligó a disponer de información fidedigna sobre el escenario en que se desarrollarían las operaciones, lo que llevó a Vidal Gormaz a reunir noticias relativas al litoral de Atacama y Tarapacá. Entonces publicó una nueva edición de la Geografía Náutica de Bolivia, acompañada de una carta del Desierto de Atacama; editó un folleto titulado Noticias del Desierto i sus recursos, fechado en marzo de 1879 y en el que se describen los caminos que llevaban desde

43 Аnи. hidro., II, 1876, IX. 
Antofagasta al interior de la provincia; y editó la Geografía Náutica y Derrotero de las costas del Perú con información hidrográfica y náutica, noticias sobre el movimiento comercial de los puertos y, también, datos actualizados sobre las defensas del Callao. ${ }^{44}$

La Oficina Hidrográfica publicó también en 1879 las Noticias del Departamento Litoral de Tarapacá, con un mapa de Alejandro Bertrand, y las Noticias de los departamentos de Tacna, Moquegua y Arequipa i algo sobre la hoya del Lago Titicaca, con un plano del lago y sus comunicaciones con la costa hacia el sur. Después dio a la prensa las Noticias sobre las provincias litorales correspondientes al departamento de Lima i de la provincia constitucional del Callao. Ofreciendo así información y antecedentes de evidente actualidad y utilidad a las tropas en campaña, pero también contribuyendo al conocimiento del litoral del Pacífico sur.

En el curso del conflicto, la Oficina Hidrográfica recibió nuevas informaciones y noticias sobre el escenario de la guerra que hicieron posible rectificar y completar el trabajo sobre Tarapacá y el mapa de su costa, lo que permitió una nueva edición. Otras publicaciones de la Oficina en 1880 fueron un Estudio sobre el puerto de Iquique; las Noticias sobre las provincias litorales correspondientes a los departamentos de Arequipa, Ica, Huancavelica y Lima, acompañadas de un mapa de la costa del Perú; y Datos sobre los recursos y las vías de comunicación del litoral de las provincias de Chancay y de Lima. En 1881, Vidal Gormaz recibió el encargo de hacer un estudio sistemático del litoral peruano, pero las operaciones militares en curso lo obligaron a limitarse a las radas de Antofagasta e Iquique..$^{45}$ Sólo en el año 1884, concluida la guerra, se pudieron reanudar las comisiones hidrográficas, tanto por el norte como por el sur en los canales de la Patagonia.

Fruto del esfuerzo realizado hasta fines de la década de 1870, entre 1879 y 1884 fue apareciendo la Geografía Náutica de Chile cuya preparación fue uno de los objetivos establecidos en la norma que creó la Oficina Hidrográfica en 1874. Era una síntesis actualizada de la hidrografía de las costas de Chile, que incluía las comisiones inglesas y las expediciones nacionales de reconocimiento emprendidas hasta entonces. La obra se inició en 1879 con las «Instrucciones sobre el puerto de Corral y Río Valdivia», con seis capítulos relativos a las costas de Valdivia y Cautín hasta

44 Véase Couyoumdjian, 2013.

45 Ibidem, 2013. 
el río Toltén. Se trataba de un trabajo independiente; sin embargo, hubo un cambio de planes. La segunda entrega cubre el litoral entre el río Toltén y el Banco de las Malenas al norte de la playa de Ritoque en las cercanías de Valparaíso. La tercera entrega, aparecida en 1881, describe la costa desde el puerto de Quintero hasta la Punta Mejillones del Sur, en los $23^{\circ}$ de latitud sur, e incluyen las islas Esporádicas: San Félix y San Ambrosio, Sala y Gómez, el archipiélago de Juan Fernández y la isla de Pascua o Rapa Nui. En 1883, la cuarta entrega, abarca la costa al sur de Valdivia y Chiloé, incluyendo el litoral del canal de Chacao y el seno de Reloncaví, y la descripción de las riberas del lago Llanquihue, el golfo de Ancud y la parte oriental de la Isla Grande para terminar con el litoral de Llanquihue y Chiloé hasta Punta Galera. La quinta entrega, de 1884, aborda el litoral norte desde Mejillones al río Locumba en el Perú, cubriendo las provincias de Tarapacá y Tacna, incorporadas a la soberanía chilena después de la firma del tratado de Ancón con el Perú en1883.

Como ha sido establecido, «tomada en su conjunto, la Geografía Náutica de Chile entrega una descripción de las costas de Chile desde la frontera norte hasta Chiloé», y era la expresión material, concreta y afortunada de la hidrografía nacional y sus sucesivas campañas. Cierto que, como el propio Vidal Gormaz lo advertía, había regiones todavía malamente conocidas, por ejemplo el canal de Chacao:

\begin{abstract}
Este canal ofrece algunos peligros para la navegación, ordinariamente exagerados por falta de una buena hidrografía de él, no menos que por la dificultad que oponen las violentas corrientes del flujo y reflujo de las mareas para fijar las sondas, los arrecifes y los bajos. Estos motivos hacen que hasta el presente asistan algunas dudas sobre la existencia de varias rocas, y asimismo respecto de la verdadera posición de los peligros reales. Procuraremos sacar de las mejores fuentes la realidad de los hechos y no alterarla hasta que mejores estudios vengan a desvanecer los peligros imaginarios o confirmar su existencia. ${ }^{46}$
\end{abstract}

La Geografía Náutica sobrepasa largamente el ámbito de la hidrografía, pues incluye todo tipo de noticias de los sitios explorados. Pero, y tal como se estila en los derroteros de navegación, indica para cada accidente de la costa, su dirección y distancia respecto del punto precedente y advierte sobre los riesgos asociados a la navegación en su cercanía. En el caso de los puertos principales no solamente se da a conocer las características de la rada, los vientos y corrientes que allí corren, las instrucciones para entrar

46 Vidal Gormaz, 1882, 29. 
a la misma, los obstáculos que se deben evitar, la ubicación del fondeadero y lugares para botar el lastre, sino también informaciones acerca de disponibilidad de provisiones para las naves y los precios relativos de las mismas, el volumen de su comercio de acuerdo a las estadísticas oficiales y las comunicaciones por tierra con el interior y telegráficas con el resto del país. En algunos casos consigna registros meteorológicos, datos sobre precios de los fletes, los derechos portuarios vigentes, el rango de las autoridades locales, las representaciones consulares existentes y las facilidades o dificultades para el reclutamiento de marineros. En cuanto a los ríos navegables se señalan las características de la barra en su desembocadura, y las profundidades que registra el curso de agua. ${ }^{47}$

La Geografía Náutica ofrece también las fuentes consultadas, reflejando así que era fruto de un trabajo constante desarrollado a lo largo de décadas. Ahí están las menciones a las cartas y derroteros publicados por el almirantazgo británico, los viajes de José de Moraleda y las exploraciones realizadas por oficiales de la Armada chilena. Entre ellas, el reconocimiento de Juan José Latorre en el vapor Toltén del recorrido alternativo de Corral a Valdivia por el río Tornagaleones; los antecedentes aportados por el vapor «Antonio Varas» en 1867 sobre una roca en la caleta de Queule; las exploraciones del capitán José Domingo Salamanca en la costa entre Coliumo y el río Mataquito; las de Manuel Señoret relativas a la desembocadura del río Toltén y sobre el río Bueno; la de Luis Uribe en 1874 para la costa entre Horcón y la Quebrada del Negro; y la carta de la bahía de Arauco del teniente Nicolás Moller, entre otras. También aprovecha los informes sobre la isla de Pascua de los comandantes Goñi y López que la visitaron en 1870 y 1875, además de la relación del viaje del capitán Felipe González de Haedo en 1770-1771. ${ }^{48}$ Respecto de las costas de Bolivia, así como de las situadas más al norte, se ofrece la información publicada a comienzos de 1879 , pero ahora corregida y aumentada gracias a la experiencia lograda durante y después de la Guerra del Pacífico.

En relación con la zona austral, y aprovechando lo acumulado hasta 1874, el conocimiento de las costas al sur del archipiélago de Chiloé avanzó en 1891 con la publicación del Derrotero del Estrecho de Magallanes, Tierra del Fuego y canales de la Patagonia desde el Canal de Chacao hasta el Cabo de Hornos del capitán de fragata Ramón Serrano Montaner.

47 Couyoumdjian, 2013.

48 Isla de Pascua fue incorporada a la soberanía chilena en 1888. 
Que a su vez sirvió de antecedente para el estudio hidrográfico de la zona que continuó durante todo el siglo XX. Por otra parte, el conocimiento de Chiloé aumentó evidentemente con los detallados trabajos de Roberto Maldonado, Estudios geográficos e hidrográficos sobre Chiloé, publicados en 1897. De este modo, en poco más de un siglo, desde las comisiones de José Moraleda, los hidrógrafos completaron el reconocimiento general del litoral del Pacífico sur. Una empresa de grandes alcances, que espera ser todavía ser conocida en sus detalles, pero que tiene en sus etapas imperial y nacional sus dos principales momentos, pero también su continuidad, como lo ha mostrado este texto que pretende ser también un estímulo para emprender investigaciones sobre temas hasta ahora marginales o sólo propios de entusiastas historiadores navales.

Recibido el 3 de septiembre de 2013

Aceptado el 17 de octubre de 2013

\section{Bibliografía}

Anuario Hidrográfico de la Marina de Chile, Santiago, 1875-1890.

Cordovez M., Enrique: Nuestros hidrógrafos. Marina de Chile, Valparaíso, Imprenta Roma, 1937.

Couyoumdjian, Juan Ricardo: «Francisco Vidal Gormaz: su vida, su trayectoria profesional y la Geografía Náutica de Chile», en Vidal Gormaz, Francisco, Exploraciones y reconocimientos hidrográficos, Santiago, Biblioteca Nacional, Pontificia Universidad Católica de Chile y Cámara Chilena de la Construcción, 2013, IX-LXII.

Fitz-Roy, Robert: Narrative of the Surveying Voyages of His Magesty's Ships Adventure and Beagle, Londres, Henry Colburn, 1839.

Fitz-Roy, Robert: Viajes del Adventure y el Beagle, Buenos Aires, Zagier \& Urruty Publications, 2009.

Fitz-Roy, Robert: Viajes del "Adventure" y el "Beagle”, Diario, Madrid, Catarata, DIBAM, UNAM, UACH, CSIC, 2013.

Gribbin, John y Gribbin, Mary: Fitz-Roy. Capitán del Beagle, Barcelona, Editorial Juventud, 2006.

Hidalgo Canales, Sebastián: «Proceso de conformación y afianzamiento de la imagen territorial aisenina a partir de las exploraciones llevadas a cabo entre 1792 y 1892», Tesis para optar al grado de Licenciado en Historia, Pontificia Universidad Católica de Valparaíso, Valparaíso, 2013.

La Expedición Malaspina. 1789-1794, Diario general del viaje por Alejandro Malaspina, Madrid, Museo Naval, 1987. 
Maldonado C., Roberto: Estudios geográficos e hidrográficos sobre Chiloé, Publicado por la Oficina Hidrográfica de Chile por orden del Ministerio de Marina, Santiago, Establecimiento poligráfico «Roma», 1897.

Moraleda, José de la: Diario de la navegación desde el puerto del Callao de Lima al de San Carlos de Chiloé y de este al reconocimiento del Archipiélago de Chonos y costa occidental Patágonica comprendida entre los 41 y 46 grados de latitud meridional, Manuscrito en el Museo Naval de Madrid.

Moraleda, José de la: Diarios de los viajes desde el puerto del Callao a los de Guayaquil y Panamá, y de estos al reconocimiento y demarcación de las costas de Veragua, Rica, Nicaragua y Guatemala, Manuscrito en el Museo Naval de Madrid.

Moraleda, José de la: Viage al reconocimiento de las Yslas de Chiloé. Año de 1786, Manuscrito en el Museo Naval de Madrid.

Moraleda, José de la: Viaje al puerto del Callao o de Lima, en la urca afragatada del Rey, del porte de 40 cañones, nombrada Nra. Señora de Monserrate año de 1772, Manuscrito en el Servicio Oceanográfico e Hidrográfico de la Armada de Chile.

Noticias de los departamentos de Tacna, Moquegua y Arequipa i algo sobre la hoya del Lago Titicaca. Con una carta geográfica, Santiago, Oficina Hidrográfica, Imprenta Nacional, 1879.

Noticias sobre las provincias litorales correspondientes al departamento de Lima i de la provincia constitucional del Callao por... con una carta geográfica, Santiago, Oficina Hidrográfica, Imprenta Nacional, 1879.

O'Donnell y Duque de la Estrada, Hugo: El viaje a Chiloé de José de Moraleda (1787-1790), Madrid, Editorial Naval, 1990.

Philippi, Rodulfo Amando: Viaje al desierto de Atacama. Hecho por orden del gobierno de Chile en el verano de 1853-54, Santiago, Biblioteca Nacional, Pontificia Universidad Católica de Chile y Cámara Chilena de la Construcción, 2009. Primera edición, 1860.

Sagredo Baeza, Rafael y González Leiva, José Ignacio: La Expedición Malaspina en la frontera austral del imperio español, Santiago, Editorial Universitaria y Centro de Investigaciones Diego Barros Arana, 2004.

Sagredo Baeza, Rafael: «Navegando entre ríos de nieve. El piloto Moraleda en la costa patagónica», Revista Electrónica Documento-Monumento. Edición Especial. Ríos e historia, 3, 1, 2010a, 51-72, disponible en http://200.17. 60.4/ndihr/revista-3/artigos/rafael-sagredo.pdf

Sagredo Baeza, Rafael: «Ciencia, historia y arte como política. El Estado y la Historia física y política de Chile de Claudio Gay», Sagredo Baeza, Rafael (editor), Ciencia-Mundo. Orden republicano, arte y nación en América, Santiago, Editorial Universitaria y DIBAM, 2010b, 165-233.

Serrano M., Ramón: Derrotero del Estrecho de Magallanes, Tierra del Fuego y canales de la Patagonia desde el Canal de Chacao hasta el Cabo de Hornos. 
Redactado conforme a los documentos más modernos, Santiago, Imprenta Nacional, 1891.

Simpson, Enrique M,: Viajes de exploración por los archipiélagos australes, edición y prólogo de Mateo Martinic, Chile, Ofqui editores, 2011, [1874].

Urville, J. C. Dumont D': Diario de viaje. «L' Astrolabe» y «La Zélée» en el Estrecho de Magallanes, Chile, Editorial Cuarto Propio, 2011, [1841].

Vidal Gormaz, Francisco: Geografía náutica de la república de Chile. Segunda entrega, Santiago, Imprenta Nacional, 1880.

Vidal Gormaz, Francisco: Geografía náutica de la república de Chile. Entrega tercera, Santiago, Imprenta Nacional, 1880.

Vidal Gormaz, Francisco: Geografía náutica de la república de Chile. Entrega cuarta, Santiago, Imprenta Nacional, 1882.

Vidal Gormaz, Ramón: Geografía Náutica de Bolivia, Santiago, Imprenta Nacional, 1879. 